\title{
The effect of Am241 on UK plutonium recycle options in thorium-plutonium fuelled LWRs - Part I: PWRs
}

S. L. Morrison ${ }^{1}$, and G. T. Parks ${ }^{2}$

\author{
${ }^{1}$ University of Cambridge: Engineering Department, Trumpington Street, Cambridge, CB2 1PZ. \\ slm85@cam.ac.uk \\ ${ }^{2}$ University of Cambridge: Engineering Department, Trumpington Street, Cambridge, CB2 1PZ. \\ gtp10@cam.ac.uk
}

Keywords: Thorium, plutonium, americium, disposition, spatial separation, PWR, reduced moderation, MTC, VC

\begin{abstract}
UK plutonium is expected to be managed using uranium-plutonium (U-Pu) mixed oxide (MOX) fuels in Light Water Reactors (LWRs). However, studies have shown that thorium-plutonium (Th-Pu) may be preferential. Research has mostly focussed on recycle of reactor grade Pu with limited minor actinide (MA) content. This study will determine if large quantities of americium (Am) in UK Pu may be restrictive to recycle schemes by determining the effect this has on reactivity feedback coefficients, fissile loading and incineration potential. Addition of Am is shown to result in predictable trends in reactivity feedback coefficients and spatial separation of $\mathrm{Am}$ and $\mathrm{Pu}$ is found to offer potential advantages over uniformly loaded fuel in terms of maximising fissile loading and incineration. Separation may also offer benefits in terms of targeting Am destruction, particularly if multiple recycle schemes are pursued, as this would maximise the fissile loading requirements while keeping reactivity feedback coefficients negative.
\end{abstract}

\section{Introduction}

\subsection{UK Pu stockpile}

The UK has accumulated a substantial stockpile of civil Pu from decades of operating nuclear power plants and reprocessing the spent fuel. The isotopic quality of the stockpile varies significantly due to the different reactor types that have been operated historically in the UK, their various fresh fuel compositions and typical discharge burnups, and the storage times associated with different 'batches' of reprocessed fuel. One option for managing the stockpile is long-term disposal in a waste repository. However, there are not-insurmountable engineering challenges associated with designing a long-term storage facility. With this in mind, the UK government may wish to give further consideration to alternatives such as transuranic recycling in current or advanced reactor technologies.

In its current state, UK Pu is estimated to contain roughly $4 \%$ wt Am241, which has accumulated from the decay of Pu241 (Gill, 2016). Given that the UK is due to cease all reprocessing activities by 2020 (Department for Business, Energy \& Industrial Strategy, 2018) (Nuclear Decommissioning Authority, 2018), it is reasonable to assume that any recycle scheme adopted may include burning of Am241 in- 
situ. There are, therefore, two key points to consider when assessing the viability of UK Pu recycle, namely the in-core performance of:

1. Pu-only-bearing fuels from recently reprocessed spent fuel, and

2. Pu-Am241-bearing fuels from aged spent fuel.

\subsection{Viable technologies for Pu disposition}

Many studies have considered transuranic (TRU) waste incineration using existing technologies (Galahom, 2018) (Mohamed \& Badawi, 2016) (Sahin, et al., 2012a) (Sahin, et al., 2012b), while others have considered advanced options, including but not limited to: Fast Reactors (FRs) (Wallenius \& Bortot, 2018) (You \& Hong, 2016) (Wider, et al., 2014) (Tucek, et al., 2008) (Bays, 2007); Molten Salt Reactors (Waris, et al., 2015) (Heuer, et al., 2014); Small Modular Reactors (Zou, et al., 2018); Pebble Bed High Temperature Reactors (Acir \& Coskun, 2015); High Temperature Gas-cooled Reactors (Lennox, et al., 2007); and Accelerator Driven Systems (Al Qaaod, et al., 2018). However, it has been determined that, for the purposes of UK Pu incineration, MOX fuelled Light Water Reactors (LWRs) may provide the ideal platform for Pu disposition (Nuclear Decommissioning Authority, 2014) (Institution of Mechanical Engineers, 2013) (Department of Energy \& Climate Change, 2011) (International Atomic Energy Agency, 2003) (The Royal Society, 1998). Some studies have suggested a two-fold management scheme utilising both fast and thermal systems (Collins \& Renier, 2006) (Zaetta, 2004). However, deployment of a FR fleet would likely be a longer-term option. Since the UK is moving towards expanding its LWR fleet, it is expected that thermal reactors may form the basis for recycle in the short- to medium-term (Office for Nuclear Regulation, 2017) (Nuclear Industry Association, 2015) (Office for Nuclear Regulation, 2012).

While standard U-Pu MOX options have been considered (Gul, et al., 2018) (Salam \& Hah, 2018) (Alonso, et al., 2018) (Ramirez, et al., 2016) (Haas \& Hamilton, 2007) (Cowell \& Fisher, 1999) (Schlosser, et al., 1993), studies have shown that Th-Pu MOX may provide a promising alternative (Ernoult, et al., 2015) (Lau, et al., 2014) (Revol, et al., 2013) (National Nuclear Laboratory, 2012) (Fridman \& Kliem, 2011) (International Atomic Energy Agency, 2005) (International Atomic Energy Agency, 2002) (Galperin, 1995) (Cadelli \& Lippens, 1988) (Shapiro, et al., 1977). The high conversion ratio and lack of breeding of additional Pu in the Th-cycle results in significantly lower Pu / MA content in discharged fuel compared to standard U-Pu MOX, leading to potentially lower levels of radiotoxicity and decay heat of associated waste materials compared to standard $\mathrm{UO}_{2}$ and U-Pu fuels (Hesketh \& Thomas, 2013) (International Atomic Energy Agency, 2005). In addition, potential improvements in Th-fuel based safety margins may be achievable: in particular, the potential for more favourable reactivity feedback coefficients and the possibility of increased proliferation resistance of spent fuel (Raitses, et al., 2012) (Yun, et al., 2010) (Shwageraus, et al., 2004) (Weaver \& Herring, 2003) (Lombardi, et al., 1999) (Galperin \& Raizes, 1997). While there are notable downsides to the Th-fuel cycle, specifically the lack of commercial infrastructure and the reduced worth of certain control materials (du Toit \& Naicker, 2018) (Alhaj, et al., 2016) (Lau, et al., 2014) (Insulander Bjork, et al., 2013) (Fridman \& Kliem, 2011) (Lamarsh \& Baratta, 2001), it may warrant further investigation. Th-Pu only recycle has been studied in depth (Zainuddin, et al., 2017) (Alhaj, et al., 2016) (Zainuddin, et al., 2016) (Tucker, et al., 2015) (Yun, et al., 2010) (Mittag \& Kleim, 2011) (Schram \& Klaassen, 2007) (Sorensen, et al., 2006) (Kim \& Downar, 2002) (Galperin, et al., 2000). However, it is Th-Pu-MA recycle that is of more interest with respect to UK Pu management due to the previously mentioned build-up of Am241. While some studies have addressed Am-specific recycle, these have typically focussed on U-fuels (Houas, et al., 
2016) (Hyland \& Gihm, 2011) (Grouiller, et al., 2003) (Delpech, et al., 1998). (Bays, et al., 2009) summarised findings of U-Am transmutation studies, concluding that transmutation of Am241 in a thermal spectrum reactor loaded with MOX fuel may be a viable recycle option (Cesana, et al., 2004). Part I of this study will consider Pu-Am recycle in Pressurized Water Reactors (PWRs) while Part II will consider Boiling Water Reactors (BWRs).

The incineration capability of Pu/MAs in PWRs is strongly dependent on neutron energy and this, in turn, is determined by the degree of moderation that occurs within the reactor. Moderation can be altered in several ways and the effects can be exploited in order to target incineration in different isotopes or for the purposes of fulfilling different fuel performance objectives. One way to alter the degree of moderation and the overall neutron energy spectrum is to vary the hydrogen-to-heavymetal $(\mathrm{H} / \mathrm{HM})$ ratio. Previous research has shown that there are benefits associated with increased, standard and reduced moderation in PWRs for single and multiple stage recycle schemes as summarised by (Morrison, et al., 2018). Given that there has, as yet, been no decision regarding whether a single or multiple stage scheme will be pursued, both PWRs and reduced moderation PWRs (RMPWRs) will be considered. In addition to the effect of moderation, it may also be advisable to consider spatial separation of 'clean' and 'dirty' Pu from the UK stockpile in order to best target destruction of Am, which, if not efficiently incinerated, may give rise to unacceptably high fresh fuel and/or reload requirements, resulting in positive temperature coefficients of reactivity. Spatial separation has previously been demonstrated to be neutronically advantageous due to the ability to target TRU incineration and improve neutron economy by placing Th-TRU in faster spectrum locations while placing, in most cases, fissile $U$ bred from Th (U3) in softer spectrum locations (Rahman, et al., 2012). Spatial separation can be achieved in a number of ways: for example, heterogeneous loading of fuel within a single assembly where Th-TRU pins may be placed at the centre of the assembly and Th-U3 pins at the periphery (TCUP), or through whole assembly heterogeneity (WATU) (Figure 1). Studies comparing TCUP to WATU showed that both designs allowed a satisfactory discharge burnup to be achieved while maintaining a negative Moderator Temperature Coefficient (MTC); however, reactivity was found to become positive for a beyond design basis loss of coolant accident (LOCA) (Lindley, et al., 2014a) (Lindley, et al., 2014b). Adequate shutdown margins were achievable in both cases, though this required the use of $\mathrm{B} 10$-enriched $\mathrm{B}_{4} \mathrm{C}$ rods. Limiting the pin power peaking was found to be difficult for the WATU design, resulting in a high axial form factor and an unacceptable total hot channel factor. The study concluded that the TCUP layout was, on balance, the preferable design, and it will therefore be considered in this study for the purpose of achieving spatial separation of Am within UK Pu.

When considering spatial separation of $\mathrm{Am}$ and $\mathrm{Pu}$, it may be wise to place an upper limit on the heavy metal content of the fuel. Limiting the total Pu content of the fuel may be beneficial to avoid reaching the saturation point for energy produced from U233 (Kotlyar, et al., 2017a) while Am content will be limited to a theoretical maximum based on current and projected manufacturing capabilities. This is due to the presence of strong alpha and gamma emitters and the difficulties that these introduce with regards to safe handling of Am241-bearing fuels. The Nuclear Decommissioning Authority have suggested that the Am content of UK Pu should ideally not exceed $\sim 4 \%$ if it is to be recycled before 'additional treatment costs' start being incurred. However, they note that the UK Pu stockpile will likely exceed this limit in some instances, with THORP derived Pu expected to contain up to $10 \% \mathrm{Am}$ after several decades' storage (Nuclear Decommissioning Authority, 2010) (Nuclear Decommissioning 
Authority, 2009). Am-bearing fuels have been successfully manufactured with up to $10 \%$ wt Am (French Alternative Energies and Atomic Energy Commission (CEA), 2015) and, if there is appropriate justification, a maximum of $30 \%$ may theoretically be achievable ${ }^{1}$. (Collins, et al., 2007) determined that, due to the negative breeding effects of Pu241, it may be ideal to allow decay to Am241. Cooling periods of 30+ years, resulting in $~ 75 \%$ reduction in Pu241 inventories, were suggested. In the case of the UK stockpile, this cooling period has been achieved for some of the older batches of spent nuclear fuel.

Since the UK stockpile will contain varying amounts of Am depending on the decay time of individual batches, and Am content may be higher if it is further separated from Pu to allow fabrication of concentrated Am pins, this study will consider Am limits up to and including the predicted maximum amount of Am that can be feasibly included in manufacture.

Figure 1 TCUP (left) and WATU (right) designs for spatial separation of TRU (blue) and U3 (green) (Lindley, et al., 2014b)
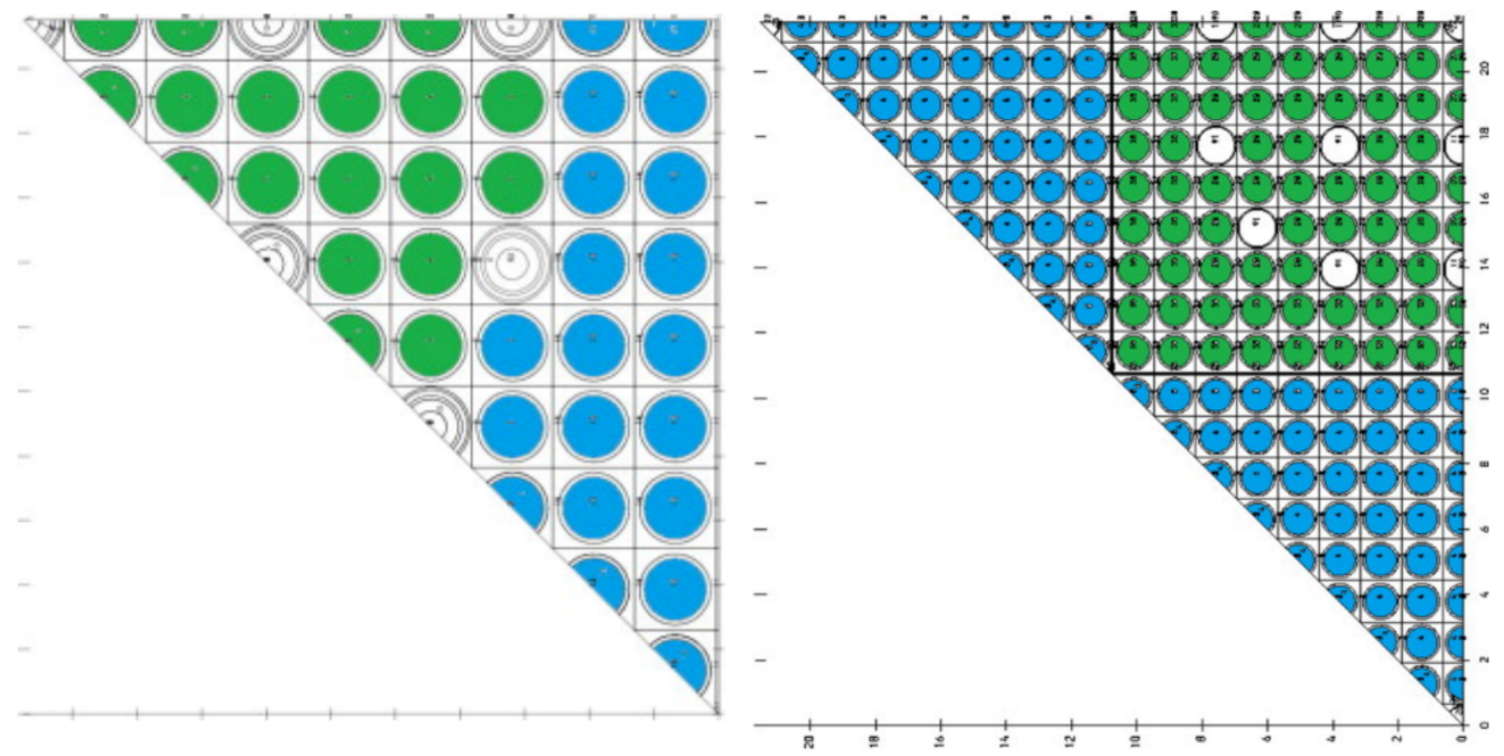

\subsection{Effect of Am on performance}

Before undertaking a detailed analysis of the benefits of separating $\mathrm{Pu} / \mathrm{Am}$, it may be useful to determine how sensitive key in-core safety parameters are to increases in Am loading. Previous research has shown that the presence of $\mathrm{Am}$ in UK Pu, and its addition to Th-Pu MOX fuel, results in a flatter effective multiplication factor (keff) versus burnup curve compared with standard grades, due to the absorption peaks of Am241 existing at higher energies than the main fission peaks of fissile isotopes (Morrison, et al., 2018). This results in a greater fraction of neutrons being absorbed during

${ }^{1}$ Pu238 ( $T_{1 / 2}=88$ years) has historically been limited to $~ 6 \%$ in MOX fuel (Baetsle, 1995). Am241 has a significantly lower heat burden but similar alpha-decay energy properties to Pu238. Therefore, it may be assumed that the maximum \%wt Am that can be included in manufacture can be determined from the maximum \%wt Pu238. Since the half-life of Am241 is five times greater ( $T_{1 / 2}=432$ years) than Pu238, the maximum \%wt can reasonably be scaled by a factor of 5 , resulting in a maximum theoretical \%wt of $30 \%$ for Am241. 
moderation. Increasing the Am content of the fuel with a view to flattening the keff curve may offer potential advantages in terms of a smaller reactivity swing, which may potentially reduce the burden on reactivity controls. This would be advantageous given that Th-fuels are already associated with increased control requirements. However, it was shown that MTC and Void Coefficient (VC) are highly sensitive to changes in the neutron energy spectrum, brought about by varying the isotopic composition of the fresh fuel and/or altering the hydrogen-to-heavy-metal (H/HM) ratio and so trends observed in the previous study may not necessarily indicate how UK Pu might perform when the Am241 content is varied. Adding Am will harden the spectrum, which may be beneficial if perturbations cause the average neutron energy to shift away from the major resonant fission peaks of fissile isotopes such as Pu239 and Pu241 or towards the major resonant absorption peaks of Am241; however, it may be disadvantageous if it results in a shift in average neutron energy towards the key resonant fission peaks of U233 (at end-of-cycle (EOC)) or causes an unacceptable increase in fast fissions in both fissile and fissionable isotopes (including Am241 itself). In addition, increases in the amount of Am241 will result in higher fissile loading requirements to maintain an acceptable keff throughout the cycle. This increases the likelihood that MTC and VC will become positive. The only potential offset against the positive contributions to reactivity feedback coefficients in fuels with a higher fissile content is breeding of Am242m from Am241. Am242m has the largest fission cross section in the thermal energy region and this decreases with increasing neutron energy. Reductions in moderator/coolant density may therefore result in large negative reactivity feedback effects as the average neutron energy increases.

Once it has been determined if there are any predictable trends in the MTC/VC response of UK Pu with increasing Am content, total Pu/Am limits can be identified and the efficiency of different lattice types can be considered from the point of view of maximising total Pu loading and achieving suitable $\mathrm{Pu} / \mathrm{Am}$ incineration rates. Based on these findings, the benefits of spatial separation can be considered in comparison to uniform fuel loading.

\section{Method}

\subsection{Pu vectors and model set-up}

Different UK Pu vectors are considered for an initial single-pass recycle study in standard and reduced moderation PWRs in order to determine the effect of varying the Am content of the fuel. These compositions have been based on the predicted UK Pu vector and have been scaled in line with increasing Am content. The first three Pu vectors detailed in Table 1 consider three bounding cases for the UK Pu stockpile based on a single lumped mass Pu vector:

1. Recently reprocessed, and therefore isotopically 'clean', Pu (0\%wt Am),

2. Isotopically averaged 'as is' Pu (3.91\%wt Am), and

3. Aged Pu, where all Pu241 has decayed to Am241 (5.60\%wt Am).

The additional Pu vectors assume incremental increases in Am241 up to 30\%wt. 
Table 1 Isotopic composition of plutonium vectors

\begin{tabular}{llllllll}
\hline \multicolumn{7}{l}{$\begin{array}{l}\text { Am } \\
\text { content } \\
\text { (\%wt) }\end{array}$} & \multicolumn{7}{l}{ Isotopic composition (\%wt) } \\
\hline Clean & 0.00 & 0.2498 & 68.7689 & 26.7041 & 1.7588 & 2.5185 & 0.0000 \\
As is & 3.91 & 0.2400 & 66.0800 & 25.6600 & 1.6900 & 2.4200 & 3.9100 \\
Aged & 5.60 & 0.2400 & 66.0800 & 25.6600 & 0.0000 & 2.4200 & 5.6000 \\
& 10.00 & 0.2248 & 61.8920 & 24.0337 & 1.5829 & 2.2666 & 10.0000 \\
& 15.00 & 0.2123 & 58.4535 & 22.6985 & 1.4950 & 2.1407 & 15.0000 \\
& 16.00 & 0.2098 & 57.7658 & 22.4315 & 1.4774 & 2.1155 & 16.0000 \\
& 17.00 & 0.2073 & 57.0782 & 22.1644 & 1.4598 & 2.0903 & 17.0000 \\
& 18.00 & 0.2048 & 56.3905 & 21.8974 & 1.4422 & 2.0651 & 18.0000 \\
& 19.00 & 0.2023 & 55.7028 & 21.6303 & 1.4246 & 2.0400 & 19.0000 \\
& 20.00 & 0.1998 & 55.0151 & 21.3633 & 1.4070 & 2.0148 & 20.0000 \\
& 23.00 & 0.1923 & 52.9520 & 20.5622 & 1.3543 & 1.9392 & 23.0000 \\
& 30.00 & 0.1748 & 48.1382 & 18.6929 & 1.2311 & 1.7629 & 30.0000 \\
\hline
\end{tabular}

Assembly-level calculations were performed using the established reactor physics code WIMS (version WIMS10A) (Lindley, et al., 2017) (Askew, et al., 1966) and nuclear data library ENDF/B-VII (Chadwick, et al., 2006). An initial benchmarking study was carried out against published data for a Th-Pu fuelled, standard PWR (International Atomic Energy Agency, 2003) to ensure the accuracy of the model. Results were generated by first performing an approximate flux solution using 172 neutron energy groups with geometric approximations inherent to the code (Lindley, et al., 2017) and then by performing a more detailed final solution using 47 groups and the method of characteristics. Thermal and epithermal region energies are split into a larger number of groups than the fast region, as these represent the energy ranges where most interactions occur in standard and reduced moderation PWRs. Burnup calculations were performed and perturbations to temperature, density and boron concentration were included. Comparisons were made for the infinite multiplication factor (kinf) as a function of burnup and reactivity feedback coefficients (MTC, Doppler Coefficient and Boron Worth) and pin-by-pin power distributions were compared for beginning-of-cycle (BOC) and EOC. Results showed good agreement, with minor discrepancies being attributed to the differences in the older, unspecified codes and data libraries used in the IAEA study and the code used in this study. Additional validation was carried out using the Monte Carlo code Serpent (Leppanen, 2015) to determine the accuracy of results for larger perturbations (VC (fully voided)).

The benchmarked model was adapted such that a standard $17 \times 17$ PWR lattice, similar to those used in Sizewell B, could be compared to a RMPWR (reference geometry and operational parameters outlined in Table 2). The fuel pin diameter was increased from $9.5 \mathrm{~mm}$ in the PWR to $11.0 \mathrm{~mm}$ in the RMPWR to reduce the H/HM ratio in line with previously proven feasible designs (Lindley, 2014). Each assembly contained 264 zircaloy-clad fuel pins and 25 empty water holes. 
Table $\mathbf{2}$ Reference assembly geometry and operating conditions

\begin{tabular}{llc}
\hline Parameter & PWR & RMPWR \\
\hline Fuel pellet radius (cm) & 0.4095 & 0.4845 \\
Fuel pin radius $(\mathrm{cm})$ & 0.4750 & 0.5500 \\
Lattice pitch $(\mathrm{cm})$ & 1.26 \\
Fuel temperature (K) & 900 \\
Cladding temperature (K) & 600 \\
Moderator temperature (K) & 585 \\
Moderator density (g/cc) & 0.7007 \\
Boron concentration $(\mathrm{ppm})$ & 500 \\
Assembly power $(\mathrm{kW} / \mathrm{cm})$ & $6.19^{2}$ \\
\hline
\end{tabular}

The theoretical densities of $\mathrm{PuO}_{2}$ and $\mathrm{ThO}_{2}$ were assumed to be $11.5 \mathrm{~g} / \mathrm{cc}$ and $10.0 \mathrm{~g} / \mathrm{cc}$ respectively. For all fuel materials used, the assumed density is $95 \%$ of their corresponding theoretical density. For purposes of comparison, several design constraints were fixed: the soluble boron concentration was fixed at $500 \mathrm{ppm}$; the assembly linear power rating was assumed to be $\sim 6.2 \mathrm{~kW} / \mathrm{cm}$; and thrice-burned fuel was expected reach a total discharge burnup of $60 \mathrm{GWd} / \mathrm{tHM}$. For a three-batch fuel management scheme with a discharge burnup of $60 \mathrm{GWd} / \mathrm{tHM}$, keff of 1.03 (or more) was required up to 40 $\mathrm{GWd} / \mathrm{tHM}$. This keff value accounts for the effects of neutron leakage, which is typically $~ 3 \%$ in PWRs.

\subsection{Reactivity feedback coefficients}

Changes in reactivity for MTC and VC were calculated using Equation 1.

$$
\Delta \rho=\frac{k_{\infty}^{p}-k_{\infty}^{n}}{k_{\infty}^{p} \cdot k_{\infty}^{n}} \frac{1}{\Delta X}
$$

Equation 1

where $n$ and $p$ refer to nominal and perturbed conditions respectively and $X$ represents the change in moderator temperature or \% voiding outlined in Table 3.

Table 3 Perturbed operating conditions

\begin{tabular}{ll}
\hline Coefficient & Perturbation \\
\hline MTC & $\begin{array}{l}\text { moderator temperature }+5 \mathrm{~K} \\
\text { moderator density reduced to } 0.6886 \mathrm{~g} / \mathrm{cc}\end{array}$ \\
VC (90\% void fraction) & moderator density reduced to $0.07 \mathrm{~g} / \mathrm{cc}^{3}$ \\
VC (fully voided) & moderator density reduced to $0.01 \mathrm{~g} / \mathrm{cc}^{4}$ \\
\hline
\end{tabular}

\subsection{Isotopic contribution to reactivity feedback coefficients}

Isotopic contributions to reactivity feedback coefficients are determined as per (Ganda \& Greenspan, 2010). Where "the major contributors to the reactivity coefficient are fissile isotopes, it is more

\footnotetext{
${ }^{2}$ Assumed equal to the assembly power of Sizewell B when fuelled with $3.1 \%$ enriched $\mathrm{UO}_{2}$ (Meyer \& Stokke, 1997)
}

${ }^{3}$ Representing a 90\% void fraction (VF) as per typically accepted regulatory limits (AREVA/EDF, 2012)

\footnotetext{
${ }^{4}$ Representing an extreme LOCA
} 
convenient to rank the constituent contribution by the number of fission neutrons they emit per neutron absorbed in the system". Normalizing "per absorbed neutron", $k_{\infty}$ is broken down as per Equation 2:

$$
\begin{aligned}
k_{\infty}=\eta . f=\frac{\sum_{j} v_{j} \Sigma_{f j} \Phi_{j}}{\sum_{i} \Sigma_{a i} \Phi_{i}}=\frac{v_{1} \Sigma_{f 1} \Phi_{1}}{\sum_{i} \Sigma_{a i} \Phi_{i}}+\frac{v_{2} \Sigma_{f 2} \Phi_{2}}{\sum_{i} \Sigma_{a i} \Phi_{i}}+\cdots \\
=\frac{v_{1} \Sigma_{f 1} \Phi_{1}}{\sum_{a 1} \Phi_{1}} \cdot \frac{\sum_{a 1} \Phi_{1}}{\sum_{i} \Sigma_{a i} \Phi_{i}}+\frac{v_{2} \Sigma_{f 2} \Phi_{2}}{\sum_{a 2} \Phi_{2}} \cdot \frac{\sum_{a 2} \Phi_{2}}{\sum_{i} \Sigma_{a i} \Phi_{i}}+\cdots
\end{aligned}
$$

Equation 2

Defining $\eta$ and $f$ as:

$$
\eta_{j} \equiv \frac{v_{j} \Sigma_{f j} \Phi_{j}}{\Sigma_{a j} \Phi_{j}} ; \tilde{f}_{j} \equiv \frac{\Sigma_{a j} \Phi_{j}}{\sum_{i} \Sigma_{a i} \Phi_{i}}
$$

Equation 3

$k_{\infty}$ may then be described by:

$$
k_{\infty}=\eta_{1} \tilde{f}_{1}+\eta_{2} \tilde{f}_{2}+\cdots
$$

Equation 4

where:

$\eta_{j}$ is the total number of fission neutrons produced per neutron absorbed in component $j$

$f_{j}$ is the fraction of neutrons absorbed in component $j$ from the total neutrons absorbed in all system constituents. This definition differs slightly from the standard thermal utilization definition.

Change in reactivity due to perturbations in moderator density can then be defined as per Equation 5:

$$
R F C=\frac{k_{\infty}^{p}-k_{\infty}{ }^{n}}{k_{\infty}^{p} \cdot k_{\infty}{ }^{n}} \frac{1}{\Delta T}=\frac{1}{\Delta T} \frac{\left(\left.\eta_{1} \tilde{f}_{1}\right|_{p}-\left.\eta_{1} \tilde{f}_{1}\right|_{n}\right)+\left(\left.\eta_{2} \tilde{f}_{2}\right|_{p}-\left.\eta_{2} \tilde{f}_{2}\right|_{n}\right)+\cdots}{k_{\infty}{ }^{p} \cdot k_{\infty}{ }^{n}}
$$

Equation 5

\section{Results and discussion}

\subsection{Neutron multiplication}

To achieve a sufficient keff, the total Pu content was varied depending on the Am content of the fresh fuel and the lattice type being considered. For low Am content cases, the keff curve decreases with increasing burnup in both the PWR and RMPWR. However, for higher Am content cases, there is a slight reduction in keff early in the burnup cycle prior to an increase in keff as the cycle progresses (Figure 2). This is due to the absorbing properties of Am241 and the daughter products that exist in the transmutation chain, as discussed by (Morrison, et al., 2018). For lower Am content cases, the RMPWR requires a higher total Pu fraction in the fresh fuel to achieve the desired keff, while, for higher Am content cases, the PWR requires a higher total Pu fraction in the fresh fuel (Figure 3). As the Am content increases the difference in the total Pu requirements for the two lattice types increases.

Where a negative MTC is required, the maximum allowable Am content in the fuel is $23 \% \mathrm{wt}$ in the PWR (33.50\%wt total Pu) and 16\%wt in the RMPWR (22.50\%wt total Pu). If the fuel composition is constrained by the need to maintain a negative VC (fully voided), the maximum allowable Am content 
of the fuel is again higher for the PWR (10\%wt Am, $17.00 \%$ wt total Pu) than the RMPWR $(5.60 \% w t$ $\mathrm{Am}, 15.75 \%$ wt total $\mathrm{Pu}$ ). For each of the scenarios considered, the effect of increasing Am was recorded and the isotopic contributions towards total MTC and VC have been determined to identify key trends and overall effect on the sign and magnitude of the coefficients.

Figure 2 Typical keff-burnup curves for UK Pu with different Pu and Am \%wt content

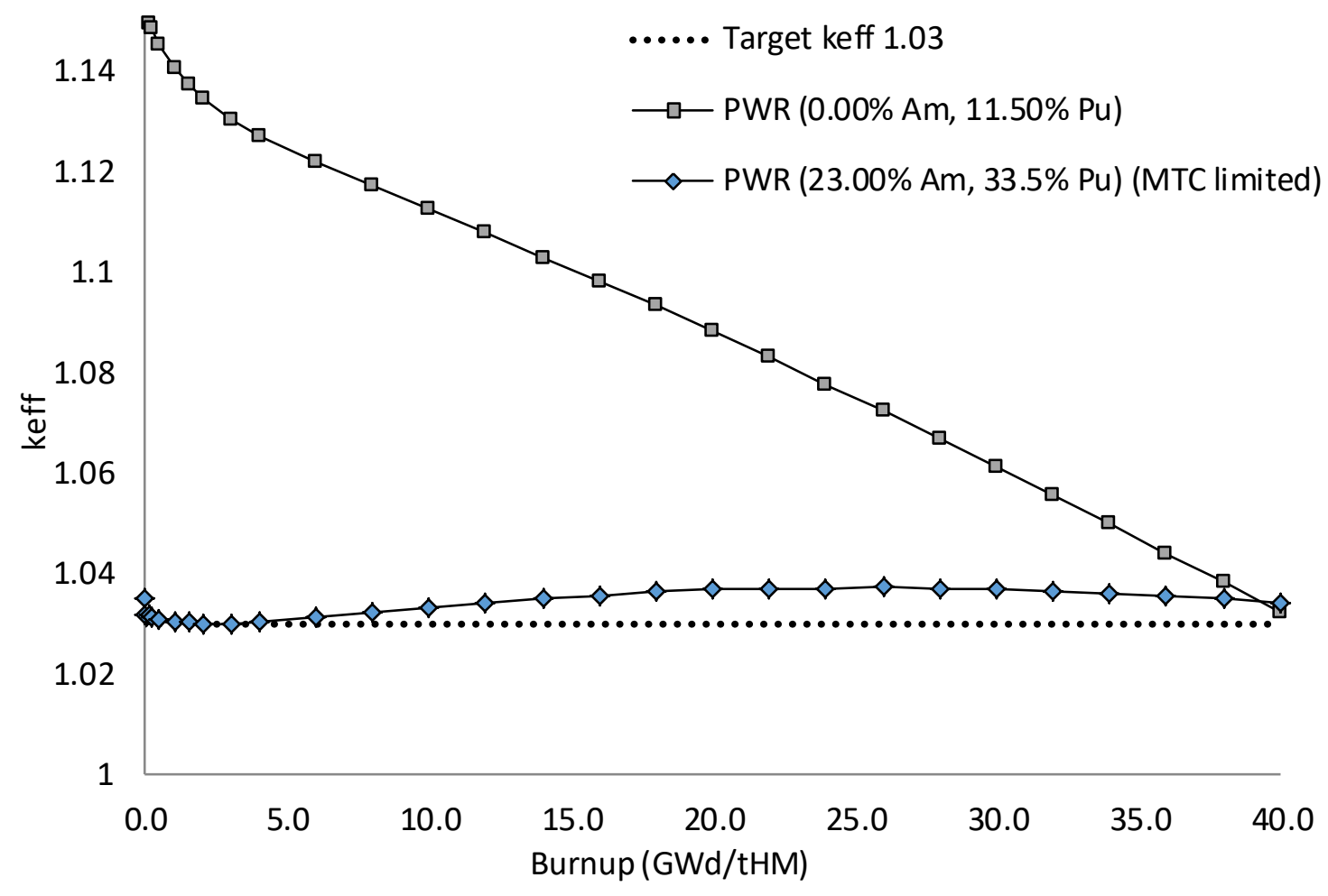


Figure 3 Total Pu required to maintain keff $\geq 1.03$ up to $40 \mathrm{GWd} / \mathrm{tHM}$ for varying Am content

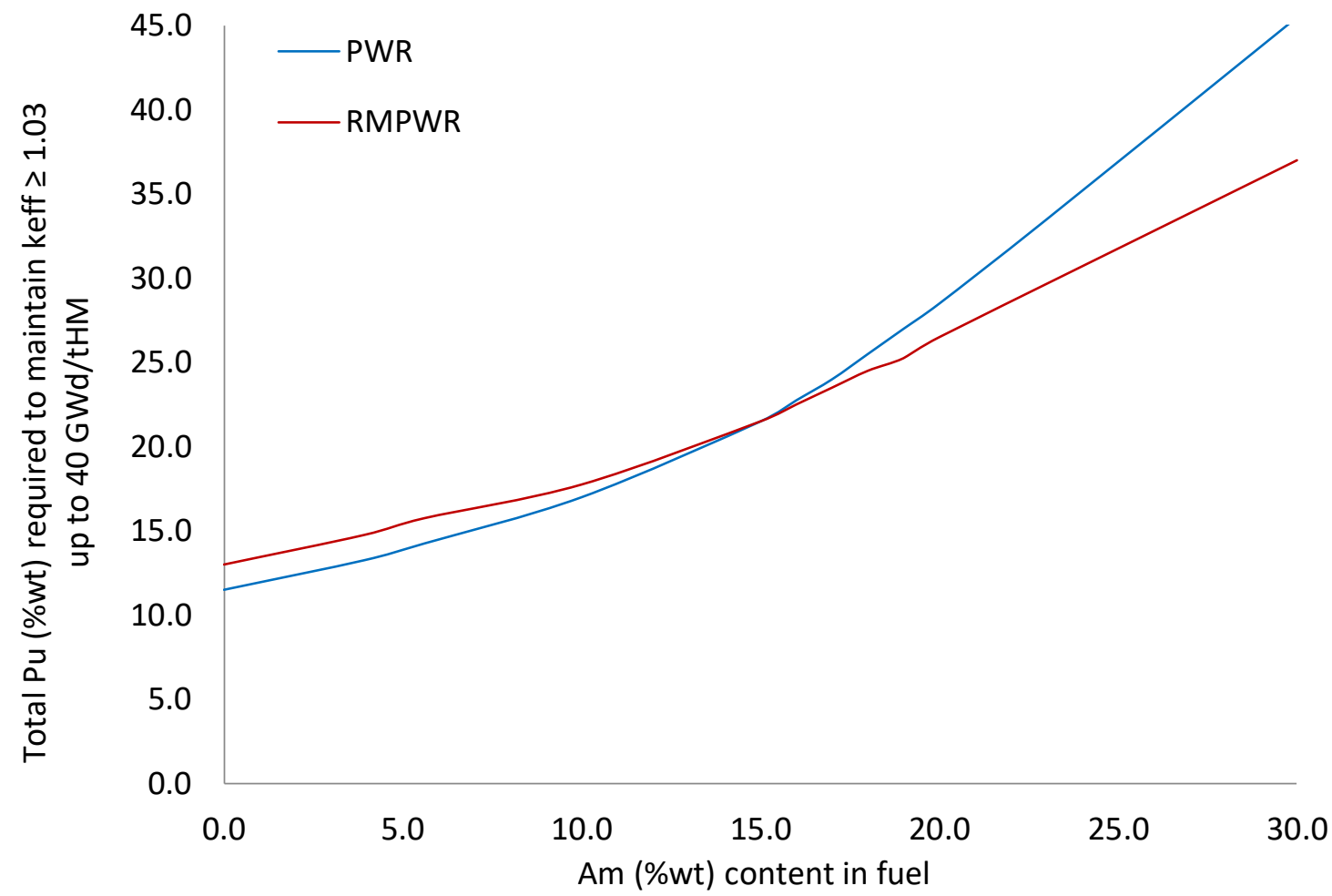

\subsection{MTC}

Figure 4 plots the variation of MTC with burnup for selected cases. It shows that, as expected, the addition of Am causes the MTC to become less negative due to the hardening effects of the presence a thermal neutron absorber and the increased Pu loading requirements that this causes. From an isotopic point of view, a harder spectrum results in a reduction in the magnitude of negative contributions from key fissile isotopes, such as Pu239, and an increase in the magnitude of the positive contributions from fissionable isotopes, such as Am241 and Pu240 (Figure 5), which ultimately leads to a less negative MTC. Perhaps unexpectedly, the MTC is consistently more negative in the PWR than the RMPWR, despite the significantly higher fraction of total Pu required to maintain an acceptable keff in the high Am cases in the PWR.

In the lower Am content cases, the MTC is more negative overall in the PWR, because the negative contributions from Pu239 and Pu241 are typically greater in the PWR than the RMPWR, while the positive contributions from all other isotopes, including fissile U233, are greater in the RMPWR. In the higher Am content cases, the contributions from most isotopes are similar regardless of reactor type. However, the discrepancy in the contributions from Pu239 (i.e. negative in the PWR and significantly less negative/more positive in the RMPWR) is large enough that the PWR continues to display an overall more negative MTC than the RMPWR.

In particularly high Am content cases, the total magnitude of contributions from Pu239 is overshadowed by the positive effects from fissionable isotopes, particularly Am241 and Pu240. This is due to the hardening of the spectrum causing a shift away from the fission peak of Pu239 such that, despite the Pu239 fraction of the fuel outweighing Pu240 and Am241 by $20-30 \% \mathrm{wt}$, these fissionable isotopes begin to dominate. For very high Am content cases such as $30 \% \mathrm{Am}$, the negative 
contributions from Am242m are not sufficient to offset the large positive contributions from Am241 and Pu240. However, for mid-range cases such as those which limit the MTC, accumulation of Am $242 m$ may have a more significant effect due to the smaller contributions from fissionable isotopes in mid-range cases compared to high Am content cases. A slightly higher fissile loading than those predicted may be possible as the WIMS code used to calculate contributions underestimates the effect of Am242m. WIMS assumes that exactly $10 \%$ of transmutations will result in Am242m; however, the branching ratio has been shown to be energy dependent with the fraction of Am242m productions increasing with increasing neutron energy/spectrum hardness (Golyand, et al., 2009).

While the fissile fraction of the fresh fuel and the presence of fissionable isotopes dictate whether the MTC is positive or negative, it is the effect of Pu239 and, to a lesser extent, Pu241 which appears to dictate which lattice type has the more negative MTC.

Figure 4 Variation of MTC with burnup for 0,18 and $30 \% \mathrm{wt} \mathrm{Am}$ in the PWR and RMPWR

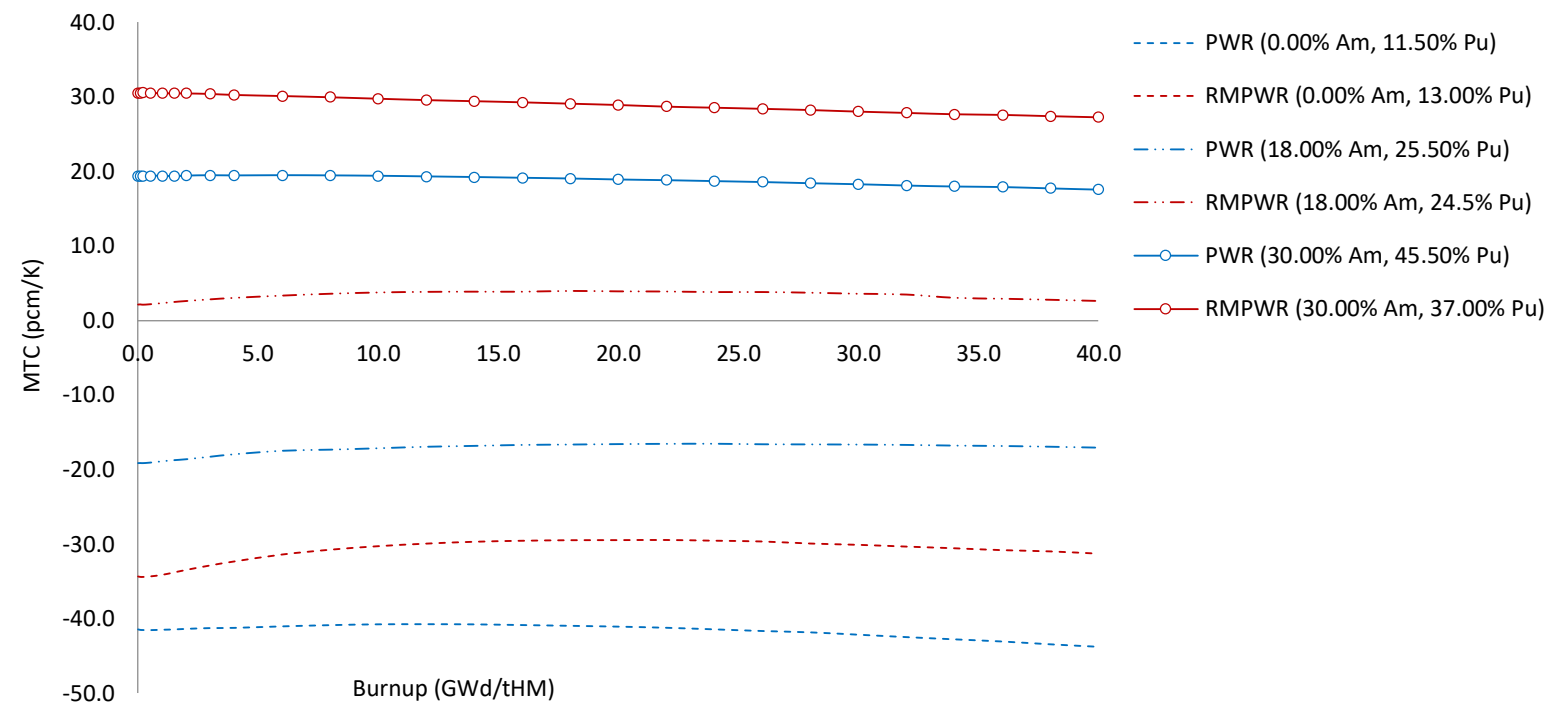

Figure 5 Major contributors to MTC for selected cases

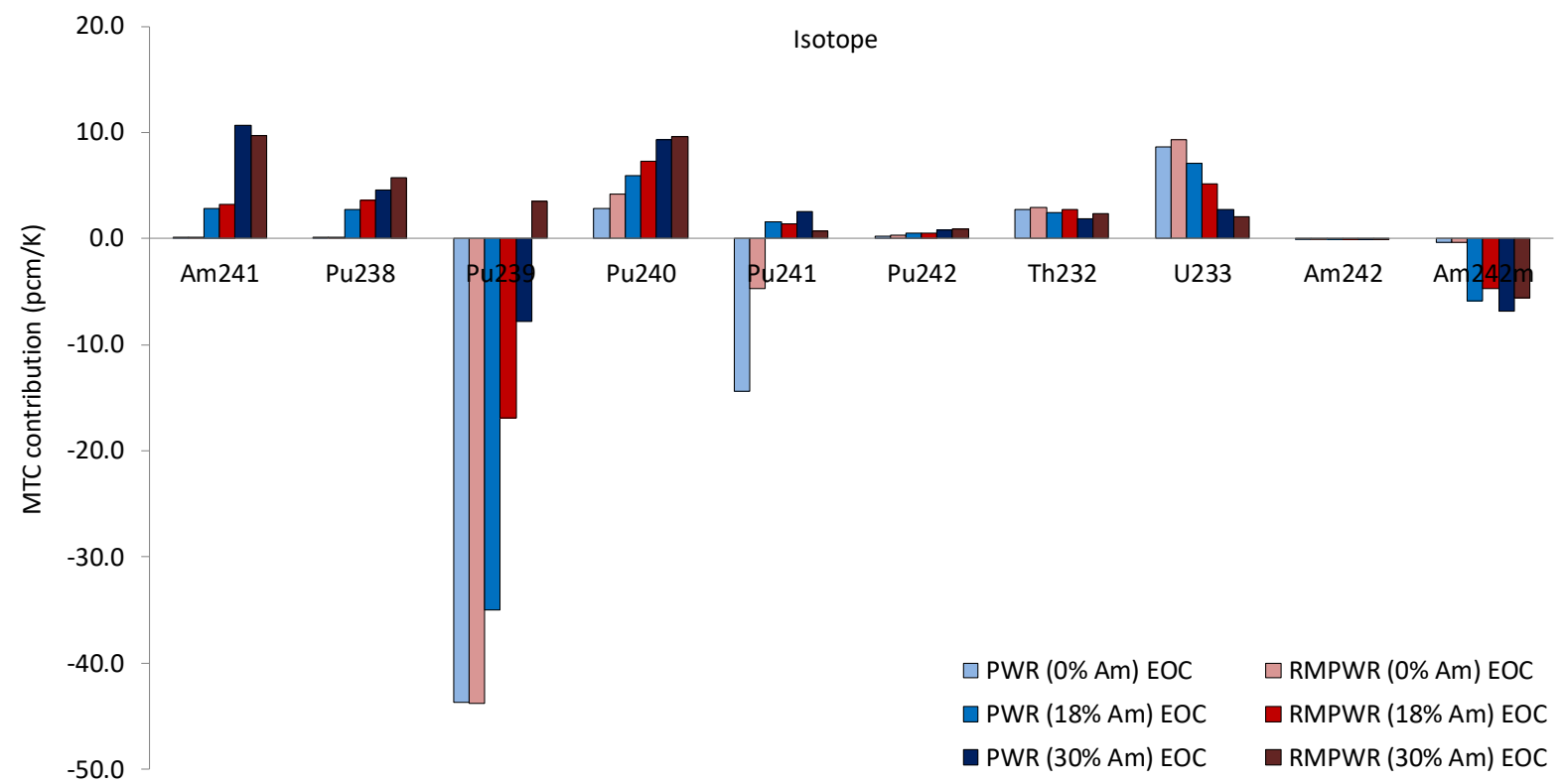


Figure 6 illustrates how the contributions from Pu239 vary with neutron energy for both lattice types considered with increasing $\mathrm{Am} / \mathrm{Pu}$ content. It shows that the negative contributions in the thermal energy region are always greater in the PWR than the RMPWR regardless of Am content and total Pu loading. This is attributable to the energy distribution of neutrons and the subsequent effect that this has on the energy-averaged microscopic cross section of the isotope. There is a higher thermal flux in the PWR than the RMPWR (Figure 7), which is more noteworthy in the lower Am case due to this being a softer, more thermal spectrum than higher Am cases. Fissile isotopes such as Pu239 have an increasingly large microscopic cross section with decreasing neutron energy in the thermal energy range, hence there is greater negative reactivity feedback in the PWR, because, while the perturbation in moderator density from 0.7007 to $0.6886 \mathrm{~g} / \mathrm{cc}$ results in a fairly equal change in flux in the PWR and the RMPWR, the average neutron energies for the nominal and perturbed cases are lower (and therefore sit further to the left of the energy spectrum) in the PWR than in the harder spectrum of the RMPWR. This results in a greater difference in the average cross section between nominal and perturbed cases in the PWR than the RMPWR. It is worth noting that, for thermal energies in the range 0.1-1 eV in the low Am case, the RMPWR displays a more negative thermal contribution than the PWR. This is because there is a large peak in the cross section of Pu239 at this energy and, since the RMPWR has a harder spectrum, the perturbation in this case results in a shift towards this peak and a subsequent negative reactivity feedback effect. As the spectrum hardens with increasing $\mathrm{Am} / \mathrm{Pu}$ content, the average neutron energy 'misses' this peak and the effect is lost.

Figure 6 Contributions to MTC from Pu239 for 0 and 30\%wt Am cases in the PWR and RMPWR at 40 GWd/tHM

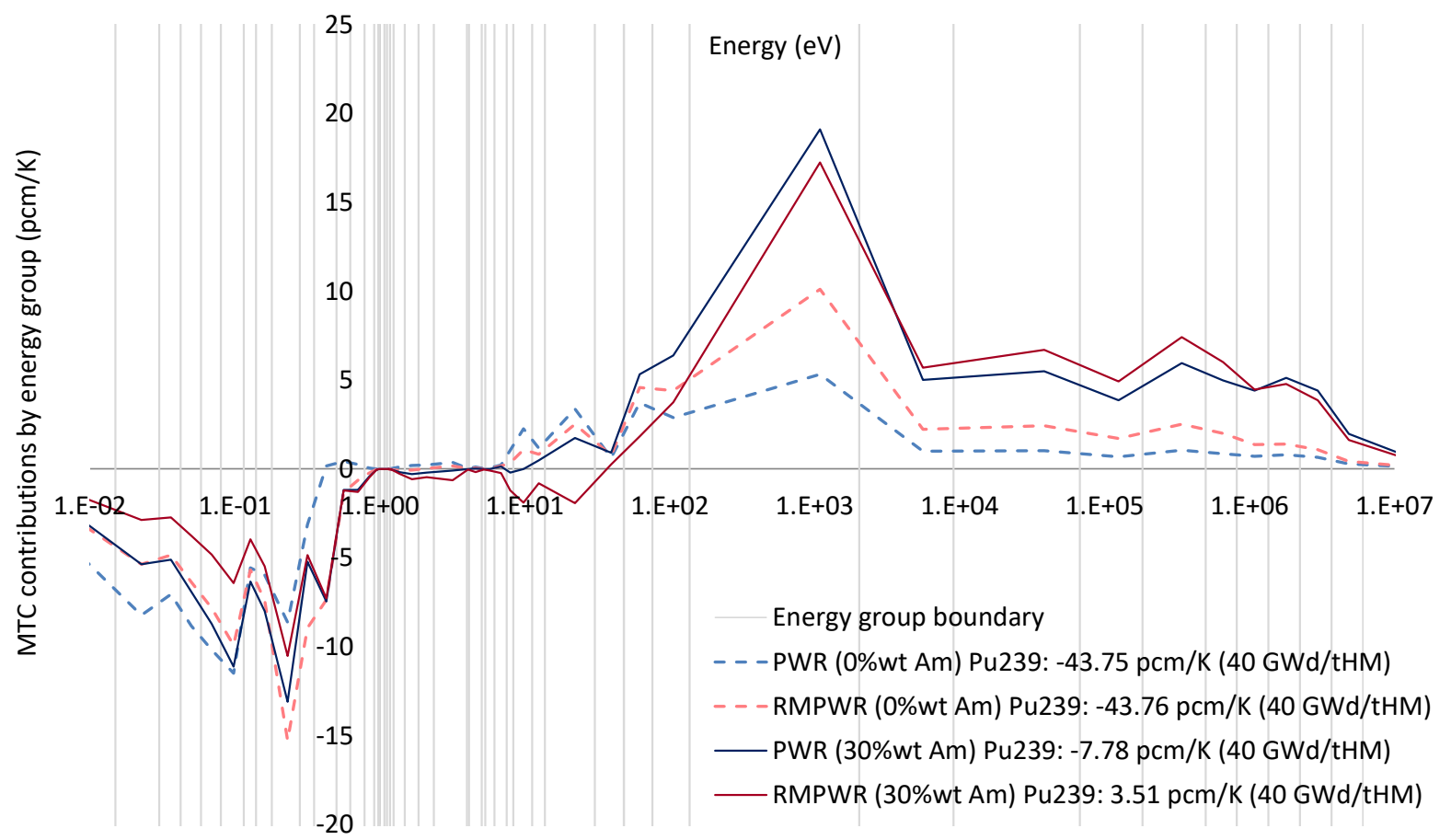

In the lower Am content cases, the negative contributions from Pu239 are far more significant than the positive epithermal contributions. A combination of a greater magnitude in negative thermal contributions and a smaller magnitude in positive epithermal contributions results in a more negative total contribution towards MTC in the PWR. As the Am/Pu content increases and the spectrum hardens, the negative thermal contributions decrease and the positive epithermal contributions 
increase. The positive epithermal contributions are more comparable in the higher Am/Pu content cases despite the difference in total Pu loading. This is because the proportion of neutrons existing at this energy is similar due to the reduction in moderation in the RMPWR and the higher fissile content in the PWR. However, the reactivity feedback in the thermal energy region, though diminished, remains significantly more negative in the PWR due to the difference in cross sections. It is this feature which causes the overall MTC to remain more negative in the PWR in the higher Am content case.

Figure 7 Thermal energy contributions to MTC (above, left-hand axis) from Pu239 for 0 and $30 \% w t$ Am cases in the PWR and RMPWR at $40 \mathrm{GWd} / \mathrm{tHM}$ compared with normalised flux (per 1000 neutrons produced) per unit lethargy (below, right-hand axis)

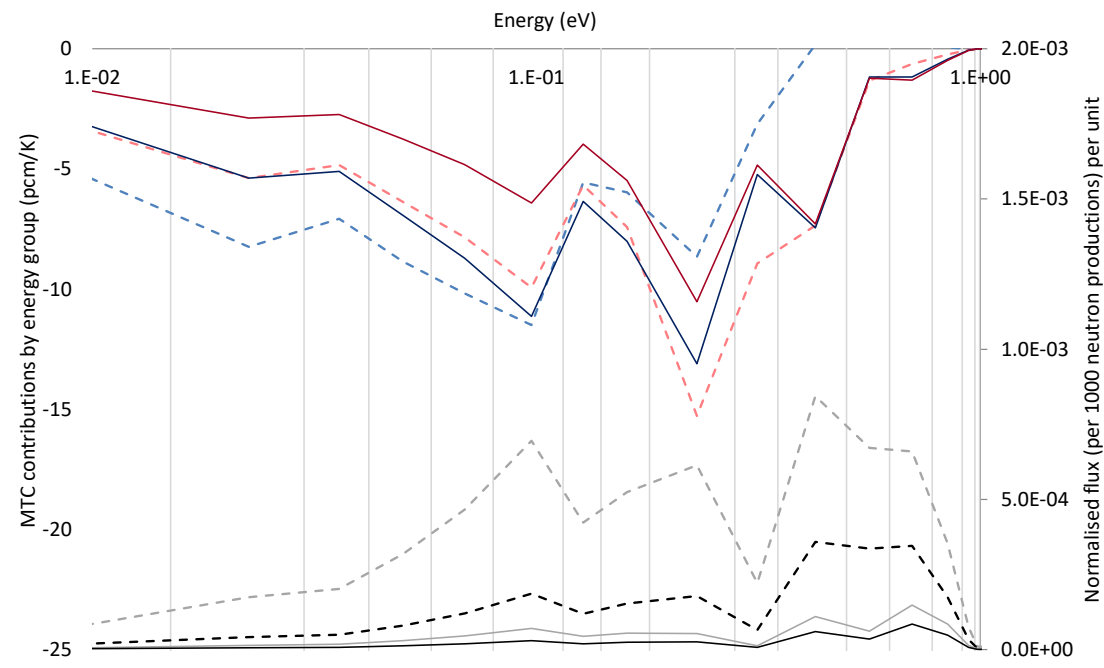

Energy group boundary

- PWR (0\%wt Am) Pu239: -43.75 pcm/K (40 GWd/tHM)

- RMPWR (0\%wt Am) Pu239: -43.76 pcm/K (40 GWd/tHM)

_ PWR (30\%wt Am) Pu239: -7.78 pcm/K (40 GWd/tHM)

क人 — RMPWR (30\%wt Am) Pu239: 3.51 pcm $/ K$ (40 GWd/tHM)

- Flux: PWR 11.5\%wt Pu (0\%wt Am): 40 GWd/tHM $(0.7007 \mathrm{~g} / \mathrm{cc})$

- - Flux: RMPWR 13.0\%wt Pu (0\%wt Am): 40 GWd/tHM $(0.7007 \mathrm{~g} / \mathrm{cc})$

Flux: PWR 44.5\%wt Pu (30\%wt Am): 40 GWd/tHM $(0.7007 \mathrm{~g} / \mathrm{cc})$

Flux: RMPWR 35.5\%wt Pu (30\%wt Am): 40 GWd/tHM $(0.7007 \mathrm{~g} / \mathrm{cc})$

The same effects are noted in the response of Pu241, since this isotope displays a similar cross section and resonance structure to Pu239. A different trend is observed in the response of U233, due to the key fission peak of this isotope existing at a slightly higher energy than those of Pu239 and Pu241. While U233 has a consistently positive effect on MTC, the magnitude of the positive contributions diminishes with increasing Am/Pu content due to increased competition with Pu239, and a change in trend is observed regarding which lattice type displays the larger positive contribution overall. In lower Am content cases, the difference in fissile loading (higher total Pu content in the RMPWR) and the effect of reduced moderation means that there is a notably harder spectrum in the RMPWR. This leads to a significantly more positive contribution in the epithermal energy region of the RMPWR than the PWR (Figure 8). This outweighs the greater negative effects in the thermal region of the PWR and the large positive reactivity effect caused by a shift in average neutron energy towards the first resonant peak of U233 in the energy range 1-10 eV. In the higher Am content cases, there remains a more significant positive contribution in the epithermal region of the RMPWR than the PWR; however, the spectrum has been hardened such that the negative thermal contributions are negligible and the perturbation in moderator density results in a shift away from the major resonant peak of U233. This shift in neutron energy results in a large negative contribution in the energy range 1-10 eV. The overall effect is that the larger positive epithermal contributions in the RMPWR are overshadowed by the negative contribution at $1-10 \mathrm{eV}$, resulting in a smaller total positive contribution in the RMPWR than the PWR. 
Figure 8 Contributions to MTC from U233 for 0 and 30\%wt Am cases in the PWR and RMPWR at 40 GWd/tHM

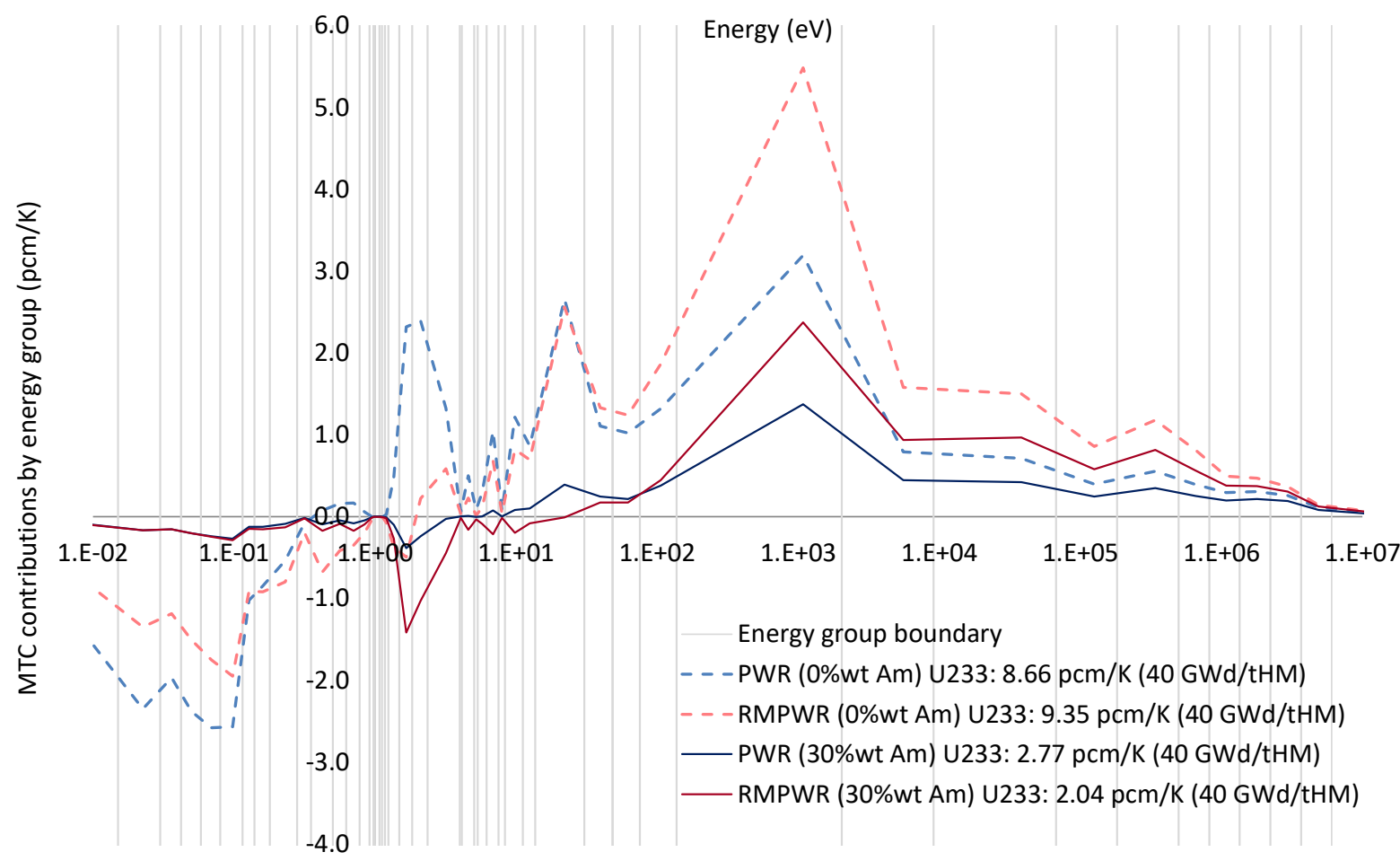

There is also a change in trend for Am241. This isotope displays a more positive contribution in the RMPWR in cases with low Am content in the fresh fuel, while a more positive contribution is observed in the PWR in cases with higher Am content. This is due to greater fast fission effects in the harder spectrum of the RMPWR in lower Am content cases and greater fast fission effects in the PWR in higher Am content cases caused by the higher total Pu content in the fuel.

While these results show that changes in spectrum are important, they suggest that it would be possible to predict the effect of changing the fuel composition for a specific lattice type if a single case has been preliminarily analysed.

\subsection{VC}

VC shows different trends to MTC. For lower Am content cases, VC is more negative in the PWR whereas, for higher Am content cases, VC is more negative/less positive in the RMPWR (Figure 9); the changeover occurs for an Am content of $\sim 18 \%$ wt. For low Am content cases, the VC is negative because of large negative contributions from fissile isotopes; in contrast to the MTC case, this includes U233 (Figure 10). The negative contributions from Pu239 and Pu241 are significantly more negative in the PWR than the RMPWR, resulting in an overall more negative VC in the PWR. In higher Am content cases, almost all isotopes display a positive contribution. Am $242 \mathrm{~m}$ again provides a predictably negative contribution, although, due to the small quantities bred, the contribution has a negligible effect. The changeover, which occurs between 17 and 19\%wt Am loading, is again caused by the difference in contributions from Pu239. In both the 17 and 19\%wt Am cases, all fissionable isotopes display larger positive contributions to VC in the PWR while some fissile isotopes, i.e. Pu241 and U233, display less negative/more positive contributions in the PWR. In the 17\% Am case, these effects are not sufficient to overcome the significant difference in contributions from Pu239, which is 
notably less positive in the PWR than the RMPWR. However, in the $19 \%$ Am case, the difference in contributions from Pu239 in the PWR and RMPWR is less significant, resulting in the combined positive contributions from fissionable isotopes outweighing the effects of Pu239.

Figure 9 Variation of VC (fully voided) with burnup for 0-30 \%wt Am in the PWR and RMPWR

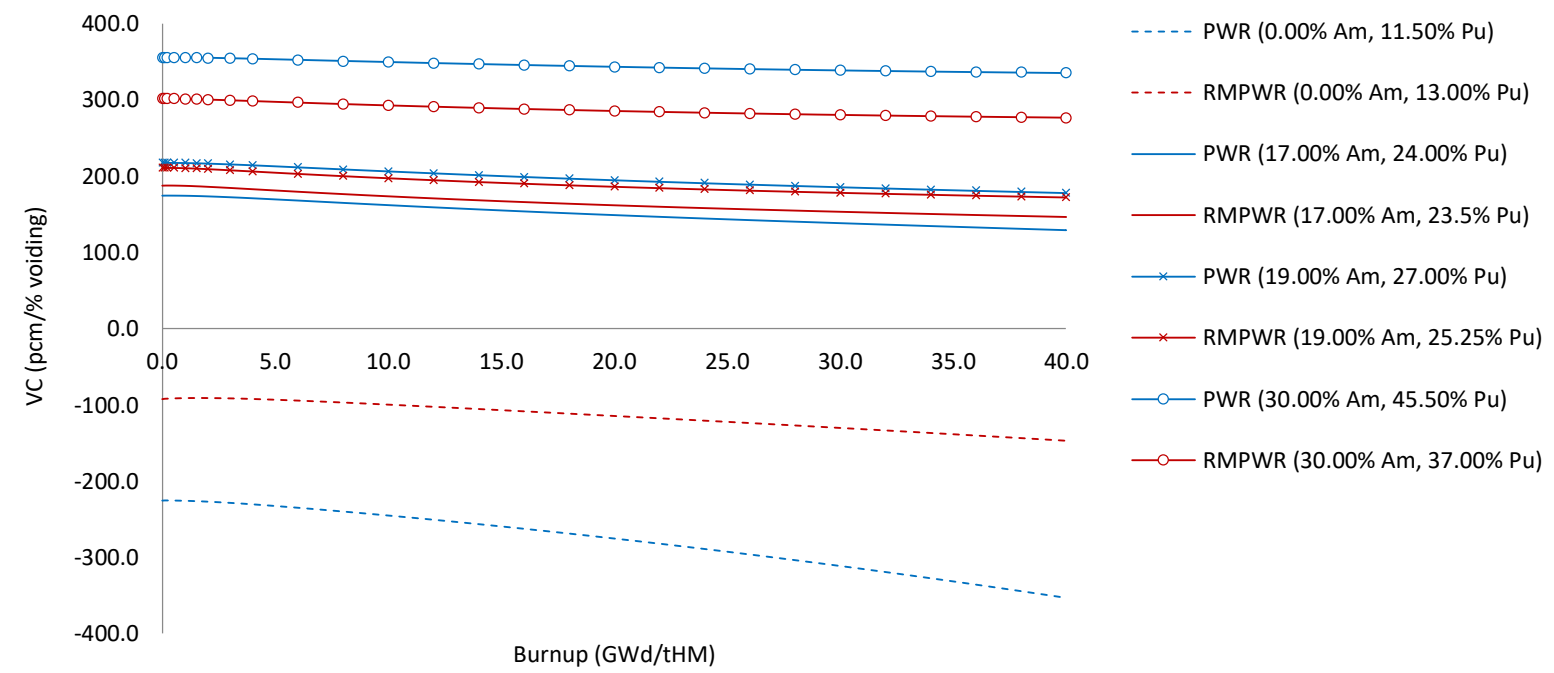

Figure 10 Major contributors to VC (fully voided) for selected cases

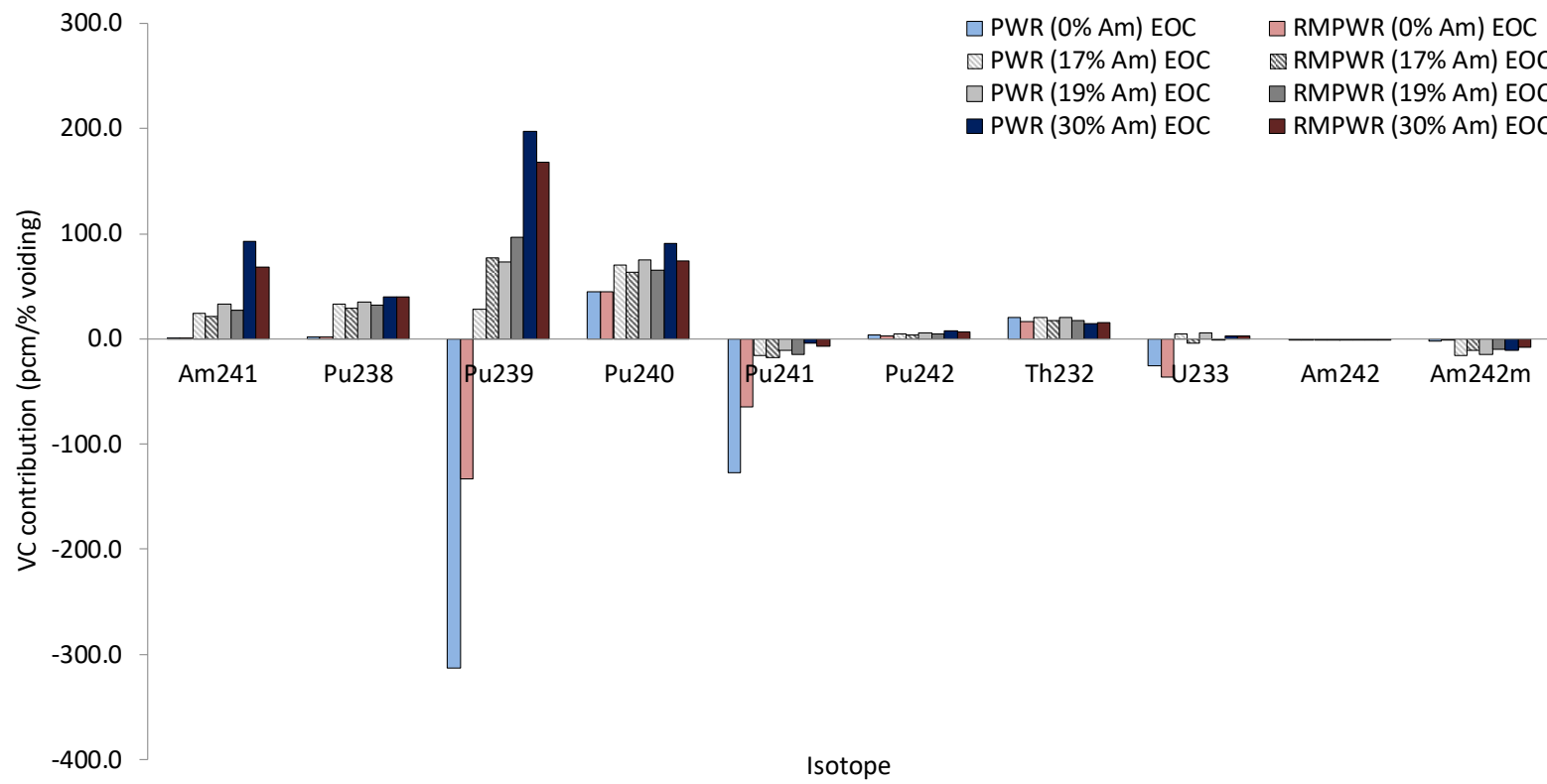

While the positive epithermal contributions from major isotopes are of a predictably large magnitude in all cases, due to the significant increase in the hardness of the spectrum as a result of the perturbation, the still relatively soft spectrum of the lower Am content cases means that the negative thermal contributions are dominant (Figure 11). In the PWR the negative thermal effects are particularly important due to the initially softer spectrum and the previously mentioned greater overall difference in microscopic cross section in the nominal and perturbed cases. As Am/Pu content increases, the negative effects are lost and the epithermal contributions and fast fission effects 
dominate. The higher fissile fraction of the PWR fuel results in larger positive contributions in the higher energy region, causing the overall VC to be more positive in the PWR than the RMPWR. The reduction in thermal negative effects shows that, in order to maintain a negative $\mathrm{VC}$, the total $\mathrm{Am} / \mathrm{Pu}$ loading must remain relatively low or engineering safeguards must be put in place to mitigate against such a substantial loss of coolant. It may be possible to design a variable fuel enrichment loading pattern, through the use of spatial separation, which capitalises on the large negative contributions in the thermal region for low Am content cases and the more negative epithermal contributions in the RMPWR in high Am loading cases.

While the MTC and, to an extent, VC may appear more favourable in the PWR and higher fissile loadings appear acceptable in this lattice type, if the MTC and VC are limiting factors, it would be worth considering the total mass of Am/Pu loaded in each design. Since the diameter of the pins in the RMPWR is greater, it may be preferable to opt for low fissile loadings in the RMPWR to incinerate higher total masses. In addition, the incineration capability of the lattices should be considered, particularly with a view to not prohibiting multiple recycle schemes.

Figure 11 Contributions to VC from Pu239 for 0 and 30\%wt Am cases in the PWR and RMPWR at 40 GWd/tHM

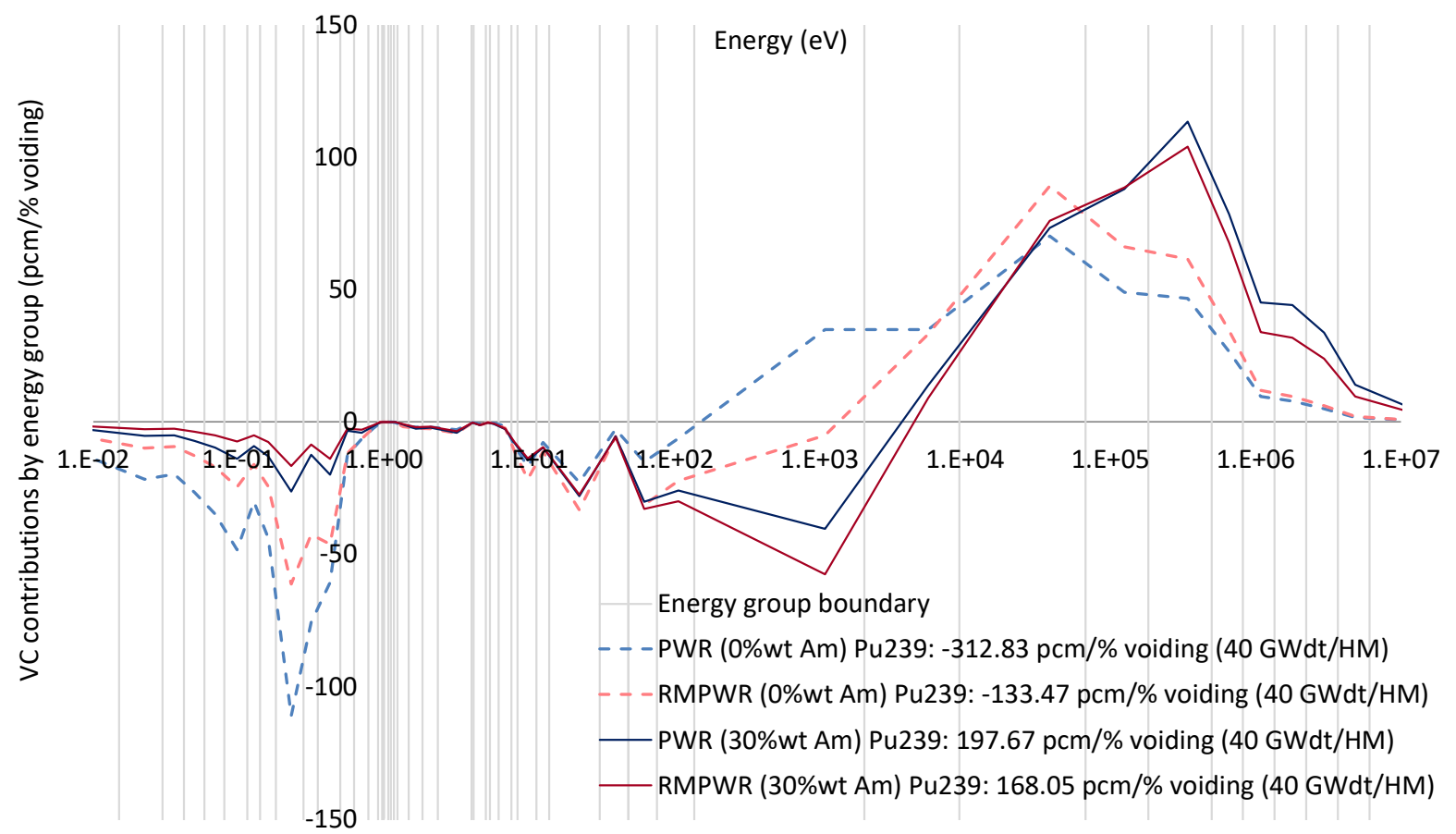

\subsection{Incineration capabilities and effects of spatial separation}

If the fresh fuel Pu vector was limited by the need to keep MTC and/or VC negative, the results suggest that the RMPWR would likely be the preferred option in both cases (Table 4). While the MTC and $90 \%$ VC were assumed to be 'hard limits' and were required to be negative throughout the cycle, the fully voided VC (99\% VF) (i.e. an extreme LOCA) was deemed to be acceptable as long as it was not substantially positive at $\mathrm{BOC}$ and was negative by MOC. In the VC limited case, the Pu and Am incineration rates are comparable; however, the total mass of Pu loaded is higher in the RMPWR. The masses compared are for $1 / 3$ core loading, as this is representative of how much fresh material would 
be loaded when each new batch is added to the core (assuming a three-batch fuel management scheme). In the MTC limited case, the total mass of Pu loaded is comparable while the fraction of initial Am and Pu incinerated is higher in the RMPWR, particularly in the Am case. Options for spatial separation have therefore been considered using the RMPWR lattice with a TCUP fuel layout, and these have been compared to the original, uniformly loaded RMPWR case. In the TCUP design, the fissile loading, incineration capabilities and reactivity feedback coefficients have been considered for the three bounding cases for UK Pu (0 (clean), 3.91\% (as is) and 5.60\% (aged) Am) in either central or peripheral pins combined with two different 'high Am content' options (10 and 15\% Am) in remaining pins (Table 5). The TCUP design has been limited to a maximum of $15 \% \mathrm{wt}$ Am - which corresponds to $\sim 20 \%$ wt total $\mathrm{Pu}$ - due to the previously mentioned need to keep the total fissile loading relatively 'low' in order to maximise the thermal negative reactivity effects in the large VC perturbation. This limit is also within theoretical fuel handling and manufacturing limits of $30 \%$.

Table 4 Pu and Am total mass loading and incineration capability for MTC and VC limiting cases

\begin{tabular}{lcccc}
\hline Parameter & \multicolumn{2}{c}{ PWR } & \multicolumn{2}{c}{ RMPWR } \\
& VC limited & MTC limited & VC limited & MTC limited \\
\hline Total Am (\%wt) & 10.00 & 23.00 & 5.60 & 16.00 \\
Total Pu (\%wt) & 17.00 & 33.50 & 15.75 & 22.50 \\
Pu loaded (kg per 1/3 core) & 4259.51 & 7367.76 & 5826.02 & 7429.19 \\
Pu loaded (kg/assembly) & 66.21 & 114.52 & 90.56 & 115.48 \\
Pu burned (\%) & 21.84 & 8.96 & 23.14 & 14.50 \\
Am loaded (kg per 1/3 core) & 476.90 & 2217.58 & 345.61 & 1425.95 \\
Am loaded (kg/assembly) & 7.41 & 34.47 & 5.37 & 22.17 \\
Am burned (\%) & 45.46 & 28.77 & 44.07 & 37.87 \\
\hline VC (90\% VF) (O GWd/tHM) & -35.29 & 202.94 & -8.56 & 122.08 \\
VC (90\% VF) (40 GWd/tHM) & -77.26 & 176.06 & -49.24 & 85.23 \\
VC (99\% VF) (O GWd/tHM) & 13.06 & 284.10 & 26.28 & 173.68 \\
VC (99\% VF) (40 GWd/tHM) & -56.81 & 254.25 & -31.55 & 131.03 \\
MTC (O GWd/tHM) & -37.32 & -2.31 & -28.27 & -3.68 \\
MTC (40 GWd/tHM) & -34.32 & -1.93 & -21.94 & -2.33 \\
\hline
\end{tabular}


Table $5 \mathrm{Pu}$ and Am total mass loading and incineration capability for TCUP cases

\begin{tabular}{|c|c|c|c|c|c|c|c|c|c|c|}
\hline Parameter & $\begin{array}{c}0 \% \mathrm{C} \\
10 \% \mathrm{P} \\
\end{array}$ & $\begin{array}{c}3.91 \% \mathrm{C} \\
10 \% \mathrm{P}\end{array}$ & $\begin{array}{c}5.60 \% \mathrm{C} \\
10 \% \mathrm{P}\end{array}$ & $\begin{array}{c}0 \% \mathrm{C} \\
15 \% \mathrm{P} \\
\end{array}$ & $\begin{array}{c}3.91 \% \mathrm{C} \\
15 \% \mathrm{P}\end{array}$ & $\begin{array}{c}10 \% \mathrm{C} \\
0 \% \mathrm{P}\end{array}$ & $\begin{array}{c}10 \% \mathrm{C} \\
3.91 \% \mathrm{P}\end{array}$ & $\begin{array}{c}10 \% \mathrm{C} \\
5.60 \% \mathrm{P}\end{array}$ & $\begin{array}{c}15 \% \mathrm{C} \\
0 \% \mathrm{P} \\
\end{array}$ & $\begin{array}{c}15 \% \mathrm{C} \\
3.91 \% \mathrm{P}\end{array}$ \\
\hline Central location: Total Am (\%wt) & 0.00 & 3.91 & 5.60 & 0.00 & 3.91 & 10.00 & 10.00 & 10.00 & 15.00 & 15.00 \\
\hline Central location: Total Pu (\%wt) & 13.00 & 14.75 & 15.75 & 13.00 & 14.75 & 17.75 & 17.75 & 17.75 & 21.50 & 21.50 \\
\hline Peripheral location: Total Am (\%wt) & 10.00 & 10.00 & 10.00 & 15.00 & 15.00 & 0.00 & 3.91 & 5.60 & 0.00 & 3.91 \\
\hline Peripheral location: Total Pu (\%wt) & 17.75 & 17.75 & 17.75 & 21.50 & 21.50 & 13.00 & 14.75 & 15.75 & 13.00 & 14.75 \\
\hline Pu loaded (kg per $1 / 3$ core) & 5687.70 & 5909.84 & 6041.76 & 6185.90 & 6408.05 & 5617.36 & 5868.16 & 6017.11 & 6058.62 & 6309.43 \\
\hline Pu loaded (kg/assembly) & 88.41 & 91.86 & 93.91 & 96.15 & 99.61 & 87.32 & 91.21 & 93.53 & 94.18 & 98.07 \\
\hline Pu burned (\%) & 23.82 & 22.25 & 21.36 & 20.74 & 19.41 & 24.24 & 22.47 & 21.48 & 21.32 & 19.82 \\
\hline Am loaded (kg per $1 / 3$ core) & 370.06 & 476.04 & 532.39 & 676.35 & 782.33 & 327.76 & 447.42 & 511.04 & 599.05 & 718.71 \\
\hline Am loaded (kg/assembly) & 5.75 & 7.40 & 8.28 & 10.51 & 12.16 & 5.09 & 6.95 & 7.94 & 9.31 & 11.17 \\
\hline Am burned (\%) & 37.58 & 41.43 & 42.99 & 36.44 & 38.72 & 39.39 & 42.76 & 44.13 & 38.71 & 40.68 \\
\hline VC (90\% VF) (0 GWd/tHM) & -26.29 & 1.35 & 16.46 & 15.50 & 41.17 & -29.48 & -0.28 & 15.51 & 10.71 & 37.97 \\
\hline VC (90\% VF) (40 GWd/tHM) & -59.90 & -36.16 & -23.65 & -13.20 & 7.45 & -65.76 & -39.25 & -25.49 & -21.74 & 1.56 \\
\hline VC (99\% VF) (0 GWd/tHM) & 3.18 & 35.38 & 54.68 & 55.42 & 83.86 & -2.02 & 32.72 & 53.26 & 48.19 & 79.07 \\
\hline VC (99\% VF) (40 GWd/tHM) & -43.74 & -14.33 & 1.18 & 16.48 & 40.73 & -52.29 & -18.87 & -1.49 & 4.59 & 32.59 \\
\hline$M T C(0 \mathrm{GWd} / \mathrm{tHM})$ & -27.51 & -24.36 & -23.60 & -22.16 & -18.60 & -28.09 & -24.60 & -23.85 & -23.12 & -19.14 \\
\hline MTC (40 GWd/tHM) & -23.09 & -20.23 & -18.66 & -17.62 & -14.70 & -23.85 & -20.64 & -18.92 & -18.74 & -15.53 \\
\hline
\end{tabular}


The results show that there is no single 'best' solution; however, some options may be more attractive than others, depending on the main objective of the recycle. If the main purpose is to reduce the total Pu stockpile as quickly as possible, it may be desirable to consider the RMPWR uniformly loaded with 16\%wt Am (MTC limited case) as this allows for the highest mass loading of Pu and Am for the cases considered. However, the VC is substantially positive for both 90 and $99 \%$ voiding. While measures can be taken to improve the VC through the use of burnable poisons (BPs) and engineering safeguards, these mitigations may introduce issues of their own which may need to be managed. For example, the use of BPs may result in increased Pu requirements to counteract suppression of keff and, since the total Pu \%wt is already relatively high, this may lead to fuel fabrication issues. In addition, the use of engineering safeguards may result in additional manufacturing costs, licensing and/or technical challenges associated with relying on mechanical safety systems. It may therefore be worth considering reducing the fissile content in the fuel to improve VC.

In the TCUP assembly loaded with 3.91\%wt (C) and 15\%wt (P) Am, the mass of Pu and Am is higher than in the uniformly loaded RMPWR 5.60\% Am (VC limited) case and the VC is significantly improved compared to the RMPWR 16\%wt Am (MTC limited) case. Similarly, the \%wt Pu and Am destroyed is greater than in the uniformly loaded MTC limited case, though it is reduced compared to the VC limited case. Placing the higher Am content pins in the centre of the TCUP assembly improves the VC compared to placing them in peripheral locations. While the VC is still positive, it is more favourable than in the MTC limited case, and would therefore require less significant reactivity controls.

If further improvements to VC are required, then other TCUP options may be considered. TCUP assemblies containing 0/15, 5.60/10 and 3.91/10 \%wt Am all involve higher masses of Pu and Am than the VC limited RMPWR. The 5.60/10 \%wt Am cases load comparable amounts of Pu to the 0/15 \%wt Am cases, but the former have higher incineration rates. Where the higher Am pins are centrally located, the VC is negative for a burnup of $40 \mathrm{GWd} / \mathrm{tHM}$ for both 90 and $99 \%$ voiding cases, and this may lead to an overall negative core VC through the use of targeted batch management schemes.

If a negative $\mathrm{VC}$ is required for the entirety of the cycle in the $90 \%$ voiding case,then results suggest that the RMPWR 5.60\% Am (VC limited) case would be preferable to the TCUP layout. The 0/10\%wt Am TCUP design is the only TCUP option considered which achieves a consistently negative VC; however, the fissile mass and \%wt Am destroyed are reduced compared to the RMPWR VC limited case.

Overall, the TCUP design shows some merit if the objective of a recycle scheme is to reduce the stockpile quickly. However, if the purpose is to maximise incineration potential, then the RMPWR VC limited case may be the preferred option. The \%wt Pu burned is marginally higher in the $0 / 10 \% \mathrm{Am}$ TCUP options, but the \%wt Am destroyed is higher in the uniformly loaded RMPWR. This, coupled with a more complex fabrication process for the TCUP layout, may lead operators to choose the simpler design.

In terms of performing multiple recycles with each of these designs, the EOC Pu vector is not so dissimilar for each of the cases after a single stage recycle that any of the options considered would prohibit a second pass through the core. However, for the cases with higher Am content in the initial Pu vector, the total required Pu loading may become prohibitive after a certain number of passes. If 
multiple recycles were to be pursued, the TCUP option would likely outperform the uniformly loaded RMPWR lattice due to its ability to target Am burning in higher Am, faster spectrum, central fuel pin locations, while using lower Am concentrations in softer spectrum, peripheral pins to maintain the desired large thermal negative contributions to VC.

\section{Conclusions}

Our previous research has shown how sensitive the limiting reactivity feedback coefficients, MTC and VC, are to isotopic and spectral effects in Th-Pu fuelled PWRs. This is because of the Pu239 content of the fresh fuel, which differs significantly between standard Pu grades and the predicted UK Pu vector. Where the Pu component of the fresh fuel remains relatively consistent - as in this study, where all $\mathrm{Pu}$ concentrations were based on UK Pu - and the isotopic variations are limited to changes in Am content in the fresh fuel, the response of the fuels to perturbations begins to display more predictable trends. The trends observed in this study may be used to predict how a given fuel type might respond if the Am/Pu content is altered - as long as an initial lattice physics study has been carried out. The results also show that, where a negative $\mathrm{VC}$ is required, operators may wish to limit the total fissile loading or attempt to make use of spatial separation, such that low Am/Pu loadings, with their larger thermal negative contributions to VC, are used to offset the dominant epithermal contributions to VC in higher Am/Pu content cases.

For the purposes of stockpile management, spatial separation of Am may offer some benefits over uniform loading of $\mathrm{Am} / \mathrm{Pu}$, depending on the purpose of the recycle scheme. Where the objective is to reduce the stockpile as quickly as possible and/or where multiple recycles are desirable, the TCUP layout with centrally located higher Am concentrations appears to be preferable in terms of maximising fissile mass loading - provided that a slightly positive VC at BOC can be tolerated or acceptably mitigated against, either through suitable batch management schemes or the addition of BPs and/or engineering safeguards. It should be noted that the cases considered in this study are by no means exhaustive and simply serve to illustrate potential options. Having identified the TCUP options which may be the most advantageous, decision-makers may wish to undertake a core loading pattern optimisation study to determine the ideal Am/Pu \%wt and layout. Further spatial separation may be considered such that there are more than two types of fuel pin within the TCUP assembly, i.e. use of low, medium and high Am content pins. Part II of this study, which focusses on spatial separation of Am in BWRs, may provide preferable alternative options for Am recycle, if the UK decides to pursue this technology as opposed to or in addition to PWRs.

\section{Data availability statement}

To the best of the authors' knowledge, this paper and references herein contain all the data needed to reproduce and validate the results presented.

\section{Acknowledgements}

The first author is grateful for the financial support of the Engineering and Physical Sciences Research Council (EPSRC) through the Imperial College, University of Cambridge and Open University Centre for Doctoral Training in Nuclear Energy under grant EP/L015900/1ICO, Thor Energy, the Whitworth Society and the Institution of Engineering and Technology. 


\section{References}

Acir, A. \& Coskun, H., 2015. Monte Carlo calculations on transmutation of plutonium and minor actinides of pebble bed high temperature reactor. Progress in Nuclear Energy, Volume 78, pp. 380387.

Al Qaaod, A. et al., 2018. Transmutation performance of uniform and nonuniform distributions of plutonium and minor actinides in TRIGA Mark II ADS reactor. Annals of Nuclear Energy, Volume 121, pp. 101-107.

Alhaj, M. Y., Badawi, A., Abou-Gabel, H. H. \& Mohamed, N. M. A., 2016. Partial Loading of ThoriumPlutonium Fuel in a Pressurized Water Reactor. Nuclear Technology, 194(3), pp. 314-323.

Alonso, G. et al., 2018. Analysis of minor actinide recycling using MOX fuel assemblies in a Boiling Water Reactor. Annals of Nuclear Energy, Volume 120, pp. 8-26.

AREVA/EDF, 2012. UK EPR Pre-Construction Safety Report: sub-chaper 14.5 (UKEPC-0002-145 Issue 08), Paris: AREVA/EDF.

Askew, J. R., Fayers, F. J. \& Kemshall, P. B., 1966. A general description of the lattice code WIMS. Journal of the British Nuclear Energy Society.

Bays, S. E., 2007. Reactor Physics Characterization of Transmutation Targeting Options in a Sodium Fast Reactor. Monterey, Joint International Topical Meeting on Mathematics \& Computation and Supercomputing in Nuclear Applications.

Bays, S. et al., 2009. Transmutation Dynamics: Impacts of Multi-Recycling on Fuel Cylce Performances, Idaho Falls: Idaho National Laboratory.

Cadelli, N. \& Lippens, M., 1988. A European investigation of MOX fuel performance in LWRs, Vienna: IAEA.

Cesana, A. et al., 2004. Some considerations on Am $242 \mathrm{~m}$ productions in thermal reactors. Nuclear Technology, Volume 148, pp. 97-101.

Chadwick, M. B. et al., 2006. ENDF/B-VII.0 Next Generation Evaluated Nuclear Data Library for Nuclear Science and Technology. Nuclear Data Sheets, Volume 107, pp. 2931-3060.

Collins, E. D., DelCul, G. D., Renier, J. P. \& Spencer, B. B., 2007. Preliminary Multicycle Transuranic Actinide Partitioning Transmutation Studies (ORNL/TM-2007/24), Oak Ridge: Oak Ridge National Laboratory.

Collins, E. D. \& Renier, J. P., 2006. Comparative Evaluation of TRU Actinide Transmutation in Fast and Thermal Burner Reactors. Trans Am Nuclear Society, Volume 95, pp. 224-226.

Cowell, B. S. \& Fisher, S. E., 1999. Survey of worldwide Light Water Reactor experience with mixed uranium-plutonium fuel (ORNL/TM-13428), Oak Ridge: Oak Ridge National Laboratory. 
Delpech, M. et al., 1998. Transmutation of americium and curium: review of solutions and impacts, s.l.: s.n.

Department for Business, Energy \& Industrial Strategy, 2018. UK strategy for radioactive discharges, London: Department for Business, Energy \& Industrial Strategy.

Department of Energy \& Climate Change, 2011. Management of the UK's plutonium stocks: A consultation response on the long-term management of UK-owned separated civil plutonium, s.l.: DECC.

du Toit, M. H. \& Naicker, V. V., 2018. Neutronic design of homogeneous thorium/uranium fuel for 24 month fuel cycles in the European pressurized reactor using MCNP6. Nuclear Engineering and Design, Volume 337, pp. 394-405.

Ernoult, M. et al., 2015. Advanced plutonium management in PWR, complementarity of thorium and uranium. Progress in Nuclear Energy, Volume 78, pp. 330-340.

French Alternative Energies and Atomic Energy Commission (CEA), 2015. Advances in research on partitioning-transmutation and plutonium multi-recycling in fast neutron reactors, Cadarache: CEA.

Fridman, E. \& Kliem, S., 2011. Pu recycling in a full Th-MOX PWR core. Part I: Steady State analysis. Nuclear Engineering and Design, 241(1), pp. 193-202.

Galahom, A. A., 2018. Reducing the plutonium stockpile around the world using a new design of VVER-1200 assembly. Annals of Nuclear Energy, Volume 119, pp. 279-286.

Galperin, A., 1995. Utilization of Light Water Reactors for Plutonium Incineration. Annals of Nuclear Energy, 22(8), pp. 507-511.

Galperin, A. \& Raizes, G., 1997. A Pressurized Water Reactor Design for Plutonium Incineration: Fuel Cycle Options. Nuclear Technology, 117(2), pp. 125-132.

Galperin, A., Segev, M. \& Todosow, M., 2000. A Pressurized Water Reactor plutonium incinerator based on thorium fuel and seed-blanket assembly geometry. Nuclear Technology, Volume 132, pp. 214-226.

Ganda, F. \& Greenspan, E., 2010. Analysis of Reactivity Coefficients of Hydride-Fueled PWR Cores. Nuclear Science and Engineering, Volume 164, pp. 1-32.

Gill, M., 2016. The potential impact of fast reactors and fuel recycling schemes on the UK's nuclear waste inventory. Manchester: University of Manchester (PhD Thesis).

Golyand, L., Shwageraus, E. \& Ronen, Y., 2009. Effect of Am(n,g) Reaction Branching Ratio on Fuel Cycle and Reactor Design Characteristics. Nuclear Science and Engineering, Issue 161, pp. 289-302.

Grouiller, J.-P.et al., 2003. Minor actinides transmutation scenario studies with PWRs, FRs and moderated targets. Journal of Nuclear Materials, Volume 320, pp. 163-169.

Gul, A., Rizwan Ali, M., Khan, R. \& Azeem, M., 2018. Neutronics analysis of CNPP-II loaded with 1/3rd MOX fuel. Annals of Nuclear Energy, Volume 120, pp. 839-844. 
Haas, D. \& Hamilton, D. J., 2007. Fuel cycle strategies and plutonium management in Europe. Progress in Nuclear Energy, Volume 49, pp. 574-582.

Hesketh, K. \& Thomas, M., 2013. The Potential Role of the Thorium Fuel Cycle in Reducing the Radiotoxicity of Long-Lived Waste - 13477. Phoenix, Waste Management Symposium.

Heuer, D. et al., 2014. Towards the thorium fuel cycle with molten salt fast reactors. Annals of Nuclear Energy, Volume 64, pp. 421-429.

Houas, M., Amrani, N. \& Boucenna, A., 2016. Evaluation of the Americium transmutation performance in high flux reactors. Annals of Nuclear Energy, Volume 97, pp. 198-203.

Hyland, B. \& Gihm, B., 2011. Scenarios for the transmutation of actinides in CANDU reactors. Nuclear Engineering and Design, 241(12), pp. 4794-4802.

Institution of Mechanical Engineers, 2013. UK Plutonium: The Way Forward, Westminster: Institution of Mechanical Engineers.

Insulander Bjork, K., Lau, C. W., Nylen, H. \& Sandberg, U., 2013. Study of Thorium-Plutonium Fuel for Possible Operating Cycle Extension in PWRs. ScienceandTechnologyofNuclearlnstallations, Volume 2013, pp. 1-8.

International Atomic Energy Agency, 2002. Thorium fuel utilization: Options and trends (IAEATECDOC-1319), Vienna: International Atomic Energy Agency.

International Atomic Energy Agency, 2003. Potential of thorium based fuel cycles to constrain plutonium and reduce long lived waste toxicity (IAEA-TECDOC-1349), Vienna: IAEA.

International Atomic Energy Agency, 2003. Status and Advances in MOX Fuel Technology, Vienna: International Atomic Energy Agency.

International Atomic Energy Agency, 2005. Thorium fuel cycle - Potential benefits and challenges (IAEA-TECDOC-1450), Vienna: IAEA.

Kim, T. K. \& Downar, T. J., 2002. Thorium fuel performance in a tight-pitch Light Water Reactor lattice. Nuclear Technology, Volume 138, pp. 17-29.

Kotlyar, D., Parks, G. T. \& Shwageraus, E., 2017a. Thorium-based plutonium incineration in the I2SLWR. Annals of Nuclear Energy, Volume 100, pp. 68-75.

Lamarsh, J. R. \& Baratta, A. J., 2001. Introduction to Nuclear Engineering. Third ed. s.I.:Prentice Hall.

Lau, C. W., Nylen, H., Insulander Bjork, K. \& Sandberg, U., 2014. Feasibility Study of 1/3 ThoriumPlutonium Mixed Oxide Core. Science and Technology of Nuclear Installations, Volume 2014, pp. 111.

Lennox, T. A., Millington, D. N. \& Sunderland, R. E., 2007. Plutonium management and Generation IV systems. Progress in Nuclear Energy, 49(8), pp. 589-596. 
Leppanen, J., 2015. Serpent - a Continuous-energy Monte Carlo Reactor Physics Burnup Calculation Code. s.I.:VTT Technical Research Centre of Finland.

Lindley, B. A., 2014. The use of reduced-moderation in Light Water Reactors for transuranic isotope burning in thorium fuel. Cambridge: University of Cambridge.

Lindley, B. A. et al., 2014b. Steady-state and transient analysis for a thorium-fuelled reducedmoderation PWR performing full transuranic recycle. Annals of Nuclear Energy, Volume 72, pp. 320337.

Lindley, B. A., Franceschini, F. \& Parks, G. T., 2014a. The closed thorium-transuranic fuel cycle in reduced-moderation PWRs and BWRs. Annals of Nuclear Energy, Volume 63, pp. 241-254.

Lindley, B. A. et al., 2017. Current status of the reactor physics code WIMS and recent developments. Annals of Nuclear Energy, Volume 102, pp. 148-157.

Lombardi, C., Mazzola, A., Padovani, E. \& Ricotti, M. E., 1999. Neutronic Analysis of U-free Inert Matrix and Thoria Fuels for Plutonium Disposition in Pressurised Water Reactors. Journal of Nuclear Materials, 274(1-2), pp. 181-188.

Meyer, G. \& Stokke, E., 1997. Description of Sizewell B Nuclear Power Plant, Halden, Norway: Institutt for energiteknikk (IFE) OECD Halden Reactor Project.

Mittag, S. \& Kleim, S., 2011. Burning plutonium and minimizing radioactive waste in existing PWRs. Annals of Nuclear Energy, Volume 38, pp. 98-102.

Mohamed, N. M. A. \& Badawi, A., 2016. Use of Thorium-Plutonium MOX in the inner pins of CANDU fuel bundles. Progress in Nuclear Energy, Volume 91, pp. 49-55.

Morrison, S. L., Lindley, B. A. \& Parks, G. T., 2018. Isotopic and spectral effects of Pu quality in Th-Pu fueled PWRs. Annals of Nuclear Energy, Volume 117, pp. 318-332.

National Nuclear Laboratory, 2012. Comparison of thorium and uranium fuel cycles - NNL (11) 11593 Issue 5, s.l.: National Nuclear Laboratory.

Nuclear Decommissioning Authority, 2009. NDA Response to Stakeholder Comments on Draft Plutonium Credible Options Paper, s.l.: Nuclear Decommissioning Authority.

Nuclear Decommissioning Authority, 2010. Plutonium: Credible Options Analysis (Gate A) (Doc Ref: SMS/TS/B1-PLUT/002/A), s.I.: Nuclear Decommissioning Authority.

Nuclear Decommissioning Authority, 2014. Progress on Approaches to the Management of Separated Plutonium, s.l.: Nuclear Decommissioning Authority.

Nuclear Decommissioning Authority, 2018. Factsheet: Spent Fuel Reprocessing. [Online] Available at: http://ukinventory.nda.gov.uk/wp-content/uploads/sites/2/2014/01/Fact-sheet-spentfuel-reprocessing.pdf [Accessed 19 September 2018]. 
Nuclear Industry Association, 2015. UK Advanced Boiling Water Reactor (UK ABWR) Justification Debate, London: Nuclear Industry Association.

Office for Nuclear Regulation, 2012. Generic Design Assessment: Design Acceptance Confirmation for the UK EPR Reactor (Ref: 2012/448621, No.: EPR70475N). Bootle: Office for Nuclear Regulation.

Office for Nuclear Regulation, 2017. Generic Design Assessment: Design Acceptance Confirmation for the Hitachi-GE Nuclear Energy LTD UK ABWR Nuclear Reactor (ONR-GDA-DAC-17-002). Bootle: Office for Nuclear Regulation.

Rahman, F. A., Franceshini, F., Wenner, M. \& Lee, J. C., 2012. Thorium fuel options for sustained transuranic burning in Pressurized Water Reactors - 12381. Phoenix, WMS Conference.

Raitses, G., Todosow, M. \& Galperin, A., 2012. Non-Proliferative, Thorium-Based, Core and Fuel Cycle for Pressurized Water Reactors, Upton: Brookhaven National Laboratory.

Ramirez, J. R. et al., 2016. Analysis of actinide recycling in a Boiling Water Reactor using CASMO4/SIMULATE-3. Progress in Nuclear Energy, Volume 89, pp. 26-38.

Revol, J. P. et al., 2013. Thorium Energy for the World: Proceedings of the ThEC13 Conference. Geneva, CERN.

Sahin, S., Ahmed, R. \& Khan, M. J., 2012b. Assessment of criticality and burn up behavior of candu reactors with nuclear waste trans uranium fuel. Progress in Nuclear Energy, Volume 60, pp. 19-26.

Sahin, S., Sahin, H. M. \& Acir, A., 2012a. Commercial utilization of weapon grade plutonium as TRISO fuel in conventional CANDU reactors. Energy Conversion and Management, Volume 63, pp. 17-24.

Salam, M. \& Hah, C. J., 2018. Comparative study on nuclear characteristics of APR1400 between 100\% MOX core and UO2 core. Annals of Nuclear Energy, Volume 119, pp. 374-381.

Schlosser, G. J., Krebs, W. \& Urban, P., 1993. Experience in PWR and BWR Mixed-Oxide Fuel Management. Nuclear Technology, Volume 102, pp. 54-67.

Schram, R. P. C. \& Klaassen, F. C., 2007. Plutonium management with thorium-based fuels and inert matrix fuels in thermal reactor systems. Progress in Nuclear Energy, 49(8), pp. 617-622.

Shapiro, N. L., Rec, J. R. \& Matzie, R. A., 1977. Assessment of Thorium Fuel Cycles in Pressurized Water Reactors, s.I.: Electric Power Research Institute.

Shwageraus, E., Hejzlar, P. \& Kazimi, M. S., 2004. Use of Thorium for Transmutation of Plutonium and Minor Actinides in PWRs. Nuclear Technology, 147(1), pp. 53-68.

Sorensen, R., Davis, J. \& Lee, J., 2006. Thorium-based fuels for enhancing plutonium transmutation in Light Water Reactors. American Nuclear Society, Volume 94, p. 87.

The Royal Society, 1998. Management of Separated Plutonium, London: The Royal Society. 
Tucek, K., Carlsson, J., Vidovic, D. \& Wider, H., 2008. Comparative study of minor actinide transmutation in sodium and lead-cooled fast reactor cores. Progress in Nuclear Energy, 50(2), pp. 382-388.

Tucker, L. P., Alajo, A. \& Usman, S., 2015. Thorium-based mixed oxide fuel in a pressurized water reactor: A beginning of life feasibility analysis with MCNP. Annals of Nuclear Energy, Volume 76, pp. 323-334.

Wallenius, J. \& Bortot, S., 2018. A small lead-cooled reactor with improved Am-burning and nonproliferation characteristics. Annals of Nuclear Energy, Volume 122, pp. 193-200.

Waris, A. et al., 2015. Comparative Studies on Plutonium and Minor Actinides Utilization in Small Molten Salt Reactors with Various Powers and Core Sizes. Energy Procedia, Volume 71, pp. 62-68.

Weaver, K. D. \& Herring, J. S., 2003. Performance of Thorium-based Mixed-oxide Fuels for the Consumption of Plutonium in Current and Advanced Reactors. Nuclear Technology, 143(1), pp. 2236.

Wider, H. et al., 2014. Synergy between Fast Reactors and Thermal Breeders for Safe, Clean, and Sustainable Nuclear Power. Petten, Joint Research Centre of the European Commission.

You, W. \& Hong, S. G., 2016. A Core Physics Study of Advanced Sodium-Cooled TRU Burners with Thorium- and Uranium-Based Metallic Fuels. Nuclear Technology, Volume 194, pp. 217-232.

Yun, D., Kim, T. K. \& Taiwo, T. A., 2010. Th/U-233 Multi-recycle in PWRs: Fuel Cycle Research \& Development (ANL-FCRD-309), s.I.: U.S. Department of Energy.

Zaetta, A., 2004. Prospective of LWRs to Reduce Minor Actinide Inventories. Paris: Nuclear Science Committee Meeting.

Zainuddin, N. Z., Parks, G. T. \& Shwageraus, E., 2016. The factors affecting MTC of thoriumplutonium-fuelled PWRs. Annals of Nuclear Energy, Volume 98, pp. 132-143.

Zainuddin, N. Z., Parks, G. T. \& Shwageraus, E., 2017. Assembly-level analysis of heterogeneous ThPu PWR fuel. Annals of Nuclear Energy, Volume 100, pp. 160-168.

Zou, C. et al., 2018. Preliminary study on TRUs utilization in a small modular Th-based molten salt reactor (smTMSR). Nuclear Engineering and Design, 339(1), pp. 75-82. 